\title{
A New General Iterative Method for Solution of a New General System of Variational Inclusions for Nonexpansive Semigroups in Banach Spaces
}

\author{
Pongsakorn Sunthrayuth ${ }^{1,2}$ and Poom Kumam ${ }^{1,2}$ \\ ${ }^{1}$ Department of Mathematics, Faculty of Science, King Mongkut's University of \\ Technology Thonburi (KMUTT), Bangmod, Bangkok 10140, Thailand \\ ${ }^{2}$ Centre of Excellence in Mathematics, CHE, Si Ayutthaya Road, Bangkok 10400, Thailand \\ Correspondence should be addressed to Poom Kumam, poom.kum@kmutt.ac.th \\ Received 4 April 2011; Accepted 8 May 2011 \\ Academic Editor: Yansheng Liu
}

Copyright (c) 2011 P. Sunthrayuth and P. Kumam. This is an open access article distributed under the Creative Commons Attribution License, which permits unrestricted use, distribution, and reproduction in any medium, provided the original work is properly cited.

\begin{abstract}
We introduce a new general system of variational inclusions in Banach spaces and propose a new iterative scheme for finding common element of the set of solutions of the variational inclusion with set-valued maximal monotone mapping and Lipschitzian relaxed cocoercive mapping and the set of fixed point of nonexpansive semigroups in a uniformly convex and 2-uniformly smooth Banach space. Furthermore, strong convergence theorems are established under some certain control conditions. As applications, finding a common solution for a system of variational inequality problems and minimization problems is given.
\end{abstract}

\section{Introduction}

In the theory of variational inequalities and variational inclusions, the development of an efficient and implementable iterative algorithm is interesting and important. The important generalization of variational inequalities called variational inclusions, have been extensively studied and generalized in different directions to study a wide class of problems arising in optimization, nonlinear programming, finance, economics, and applied sciences.

Variational inequalities are being used as a mathematical programming tool in modeling a wide class of problems arising in several branches of pure and applied mathematics. Several numerical techniques for solving variational inequalities and the related optimization problem have been considered by many authors.

Throughout this paper, we denoted by $\mathbb{N}$ and $\mathbb{R}^{+}$the set of all positive integers and all positive real numbers, respectively. Let $X$ be a real Banach space and $X^{*}$ be its dual space. Let 
$U=\{x \in X:\|x\|=1\}$ denote the unit sphere of $X$. $X$ is said to be uniformly convex if for each $\epsilon \in(0,2]$, there exists a constant $\delta>0$ such that for all $x, y \in U$,

$$
\|x-y\| \geq \epsilon \text { implies }\left\|\frac{x+y}{2}\right\| \leq 1-\delta
$$

The norm on $X$ is said to be Gâteaux differentiable if the limit

$$
\lim _{t \rightarrow 0} \frac{\|x+t y\|-\|x\|}{t}
$$

exists for each $x, y \in U$, and in this case $X$ is smooth. Moreover, we say that the norm $X$ is said to have a uniformly Gâteaux differentiable if the above limit is attained uniformly for all $x, y \in U$ and in this case $X$ is said to be uniformly smooth. We define a function $\rho:[0, \infty) \rightarrow[0, \infty)$, called the modulus of smoothness of $X$, as follows:

$$
\rho(\tau)=\sup \left\{\frac{1}{2}(\|x+y\|+\|x-y\|)-1: x, y \in X,\|x\|=1,\|y\|=\tau\right\} .
$$

It is know that $X$ is uniformly smooth if and only if $\lim _{\tau \rightarrow 0} \rho(\tau) / \tau=0$. Let $q$ be a fixed real number $1<q \leq 2$. A Banach space $X$ is said to be $q$-uniformly smooth if there exists a constant $c>0$ such that $\rho(\tau) \leq c \tau^{q}$ for all $\tau>0$. From [1], we know the following property.

Let $q$ be a real number with $1<q \leq 2$ and let $X$ be a Banach space. Then, $X$ is $q$ uniformly smooth if and only if there exists a constant $K \geq 1$ such that

$$
\|x+y\|^{q}+\|x-y\|^{q} \leq 2\left(\|x\|^{q}+\|K y\|^{q}\right), \quad \forall x, y \in X .
$$

The best constant $K$ in the above inequality is called the $q$-uniformly smoothness constant of $X$ (see [1] for more details).

Let $X$ be a real Banach space and $X^{*}$ the dual space of $X$. Let $\langle\cdot, \cdot\rangle$ denote the pairing between $X$ and $X^{*}$. For $q>1$, the generalized duality mapping

$$
J_{q}(x)=\left\{f \in X^{*}:\langle x, f\rangle=\|x\|^{q},\|f\|=\|x\|^{q-1}\right\}, \quad \forall x \in X .
$$

In particular, if $q=2$, the mapping $J_{2}$ is called the normalized duality mapping and usually, we write $J_{2}=J$. If $X$ is a Hilbert space, then $J=I$ is the identity. Further, we have the following properties of the generalized duality mapping $J_{q}$ :

(1) $J_{q}(x)=\|x\|^{q-2} J_{2}(x)$ for all $x \in X$ with $x \neq 0$,

(2) $J_{q}(t x)=t^{q-1} J_{q}(x)$ for all $x \in X$ and $t \in[0, \infty)$,

(3) $J_{q}(-x)=-J_{q}(x)$ for all $x \in X$.

It is know that if $X$ is smooth, then $J$ is single-valued, which is denoted by $j$. 
Definition 1.1. Let $C$ be a nonempty closed convex subset of $X$. A mapping $T: C \rightarrow X$ is said to be

(i) nonexpansive if

$$
\|T x-T y\| \leq\|x-y\|, \quad \forall x, y \in C,
$$

(ii) Lipschitzian if there exists a constant $L>0$ such that

$$
\|T x-T y\| \leq L\|x-y\|, \quad \forall x, y \in C,
$$

(iii) contraction if there exists a constant $\alpha \in(0,1)$ such that

$$
\|T x-T y\| \leq \alpha\|x-y\|, \quad \forall x, y \in C .
$$

Remark 1.2. We denote $F(T)$ as the set of fixed points of $T$. We know that $F(T)$ is nonempty if $C$ is bounded; for more detail see [2].

Definition 1.3. A one-parameter family $\mathcal{S}=\left\{T(t): t \in \mathbb{R}^{+}\right\}$from $C$ of $X$ into itself is said to be a nonexpansive semigroup on $C$ if it satisfies the following conditions:

(i) $T(0) x=x$ for all $x \in C$,

(ii) $T(s+t)=T(s) \circ T(t)$ for all $s, t \in \mathbb{R}^{+}$,

(iii) for each $x \in C$ the mapping $t \mapsto T(t) x$ is continuous,

(iv) $\|T(t) x-T(t) y\| \leq\|x-y\|$ for all $x, y \in C$ and $t \in \mathbb{R}^{+}$.

Remark 1.4. We denote by $F(\mathcal{S})$ the set of all common fixed points of $\mathcal{S}$, that is $F(\mathcal{S}):=$ $\bigcap_{t \in \mathbb{R}^{+}} F(T(t))=\{x \in C: T(t) x=x\}$. We know that $F(\mathcal{S})$ is nonempty if $C$ is bounded, see [3].

Let $C$ be a nonempty closed convex subset of a smooth Banach space $X$. Recall the following definitions of a nonlinear mapping $B: C \rightarrow X$, the following are mentioned.

Definition 1.5. Given a mapping $B: C \rightarrow X$,

(i) $B$ is said to be accretive

$$
\langle B x-B y, J(x-y)\rangle \geq 0, \quad \forall x, y \in C
$$

(ii) $B$ is said to be $\alpha$-strongly accretive if there exists a constant $\alpha>0$ such that

$$
\langle B x-B y, J(x-y)\rangle \geq \alpha\|x-y\|^{2}, \quad \forall x, y \in C,
$$


(iii) $B$ is said to be $\alpha$-inverse-strongly accretive or $\alpha$-cocoercive if there exists a constant $\alpha>0$ such that

$$
\langle B x-B y, J(x-y)\rangle \geq \alpha\|B x-B y\|^{2}, \quad \forall x, y \in C,
$$

(iv) $B$ is said to be $\alpha$-relaxed cocoercive if there exists a constant $\alpha>0$ such that

$$
\langle B x-B y, J(x-y)\rangle \geq-\alpha\|B x-B y\|^{2}, \quad \forall x, y \in C,
$$

(v) $B$ is said to be $(\alpha, \beta)$-relaxed cocoercive if there exist positive constants $\alpha>0$ and $\beta>0$ such that

$$
\langle B x-B y, J(x-y)\rangle \geq-\alpha\|B x-B y\|^{2}+\beta\|x-y\|^{2}, \quad \forall x, y \in C .
$$

Remark 1.6. (1) Every $\alpha$-strongly accretive mapping is an accretive mapping.

(2) Every $\alpha$-strongly accretive mapping is a $(\beta, \alpha)$-relaxed cocoercive mapping for any positive constant $\beta$ but the converse is not true in general. Then, the class of relaxed cocoercive operators is more general than the class of strongly accretive operators.

(3) Evidently, the definition of the inverse-strongly accretive operator is based on that of the inverse-strongly monotone operator in real Hilbert spaces (see, e.g., [4]).

(4) The notion of the cocoercivity is applied in several directions, especially for solving variational inequality problems using the auxiliary problem principle and projection methods [5]. Several classes of relaxed cocoercive variational inequalities have been studied in $[6,7]$.

The resolvent operator technique for solving variational inequalities and variational inclusions is interesting and important. The resolvent equation technique is used to develop powerful and efficient numerical techniques for solving various classes of variational inequalities, inclusions, and related optimization problems.

Definition 1.7. Let $M: X \rightarrow 2^{X}$ be a multivalued maximal accretive mapping. The singlevalued mapping $J_{(M, \rho)}: X \rightarrow X$, defined by

$$
J_{(M, \rho)}(u)=(I+\rho M)^{-1}(u), \quad \forall u \in X
$$

is called resolvent operator associated with $M$, where $\rho$ is any positive number and $I$ is the identity mapping.

In 2010, Qin et al. [8] introduced a system of quasivariational inclusions as follows. Find $\left(x^{*}, y^{*}\right) \in X \times X$ such that

$$
\begin{aligned}
& 0 \in x^{*}-y^{*}+\rho_{1}\left(B_{1} y^{*}+M_{1} x^{*}\right), \\
& 0 \in y^{*}-x^{*}+\rho_{2}\left(B_{2} x^{*}+M_{2} y^{*}\right),
\end{aligned}
$$

where $B_{i}: X \rightarrow X$ and $M_{i}: X \rightarrow 2^{X}$ are nonlinear mappings for all $i=1,2$. As special cases of problem (1.15), we have the following. 
(1) If $B_{1}=B_{2}=B$ and $M_{1}=M_{2}=M$, then problem (1.15) is reduced to the following. Find $\left(x^{*}, y^{*}\right) \in X \times X$ such that

$$
\begin{aligned}
& 0 \in x^{*}-y^{*}+\rho_{1}\left(B y^{*}+M x^{*}\right), \\
& 0 \in y^{*}-x^{*}+\rho_{2}\left(B x^{*}+M y^{*}\right) .
\end{aligned}
$$

(2) Further, if $x^{*}=y^{*}$ in problem (1.16), then problem (1.16) is reduced to the following. Find $x^{*} \in X$ such that

$$
0 \in B x^{*}+M x^{*} .
$$

The problem (1.17) is called variational inclusion problem denoted by $V(X, B, M)$.

Here we have examples of the variational inclusion (1.17). If $M=\partial \delta_{C}$, where $C$ is a nonempty closed convex subset of $X$, and $\delta_{C}: X \rightarrow[0, \infty)$

$$
\delta_{C}(x)= \begin{cases}0, & x \in C, \\ +\infty, & x \notin C,\end{cases}
$$

then the variational inclusion problem (1.17) is equivalent (see [9]) to finding $u \in C$ such that

$$
\langle B u, v-u\rangle \geq 0, \quad \forall x \in C
$$

This problem is called Hartman-Stampacchia variational inequality problem denoted by $\operatorname{VI}(C, B)$. if

Let $D$ be a subset of $C$, and let $P$ be a mapping of $C$ into $D$. Then, $P$ is said to be sunny

$$
P(P x+t(x-P x))=P x
$$

whenever $P x+t(x-P x) \in C$ for $x \in C$ and $t \geq 0$. A mapping $P$ of $C$ into itself is called a retraction if $P^{2}=P$. If a mapping $P$ of $C$ into itself is a retraction, then $P z=z$ for all $z \in R(P)$, where $R(P)$ is the range of $P$. A subset $D$ of $C$ is called a sunny nonexpansive retract of $C$ if there exists a sunny nonexpansive retraction from $C$ onto $D$.

In 2006, Aoyama et al. [10] considered the following problem: find $u \in C$ such that

$$
\langle A u, J(v-u)\rangle \geq 0, \quad \forall v \in C
$$

They proved that the variational inequality (1.21) is equivalent to a fixed point problem. The element $u \in C$ is a solution of the variational inequality (1.21) if and only if $u \in C$ satisfies the following equation:

$$
u=P_{C}(u-\lambda A u)
$$

where $\lambda>0$ is a constant and $P_{C}$ is a sunny nonexpansive retraction from $X$ onto $C$. 
The following results describe a characterization of sunny nonexpansive retractions on a smooth Banach space.

Proposition 1.8 (see [11]). Let $X$ be a smooth Banach space and $C$ a nonempty subset of $X$. Let $P: X \rightarrow C$ be a retraction and $J$ the normalized duality mapping on $X$. Then the following are equivalent:

(1) $P$ is sunny and nonexpansive,

(2) $\langle x-P x, J(y-P x)\rangle \leq 0$, for all $x \in X, y \in C$.

Proposition 1.9 (see [12]). Let $C$ be a nonempty closed convex subset of a uniformly convex and uniformly smooth Banach space $E$ and $T$ a nonexpansive mapping of $C$ into itself with $F(T) \neq \emptyset$. Then the set $F(T)$ is a sunny nonexpansive retract of $C$.

For the class of nonexpansive mappings, one classical way to study nonexpansive mappings is to use contractions to approximate a nonexpansive mapping [13, 14]. More precisely, take $t \in(0,1)$, and define a contraction $T_{t}: C \rightarrow C$ by

$$
T_{t} x=t u+(1-t) T_{t} x, \quad \forall x \in C,
$$

where $u \in C$ is a fixed point. Banachs contraction mapping principle guarantees that $T_{t}$ has a unique fixed point $x_{t} \in C$, that is,

$$
x_{t}=t u+(1-t) T_{t} x_{t}
$$

It is unclear, in general, what the behavior of $x_{t}$ is as $t \rightarrow 0$, even if $T$ has a fixed point. However, in the case of $T$ having a fixed point, Ceng et al. [15] proved that, if $X$ is a Hilbert space, then $x_{t}$ converges strongly to a fixed point of $T$. Reich [14] extended Browders result to the setting of Banach spaces and proved that, if $X$ is a uniformly smooth Banach space, then $x_{t}$ converges strongly to a fixed point of $T$, and the limit defines the (unique) sunny nonexpansive retraction from $C$ onto $F(T)$.

Reich [14] showed that, if $X$ is uniformly smooth and $D$ is the fixed point set of a nonexpansive mapping from $C$ into itself, then there is a unique sunny nonexpansive retraction from $C$ onto $D$ and it can be constructed as follows.

Proposition 1.10 (see [14]). Let $X$ be a uniformly smooth Banach space and $T: C \rightarrow C$ a nonexpansive mapping such that $F(T) \neq \emptyset$. For each fixed $u \in C$ and every $t \in(0,1)$, the unique fixed point $x_{t} \in C$ of the contraction $C \ni x \mapsto t u+(1-t) T x$ converges strongly as $t \rightarrow 0$ to a fixed point of $T$. Define $P: C \rightarrow D$ by $P u=s-\lim _{t \rightarrow 0} x_{t}$. Then $P$ is the unique sunny nonexpansive retract from $C$ onto $D$; that is, $P$ satisfies the property,

$$
\langle x-P x, J(y-P x)\rangle \leq 0, \quad \forall x \in C, y \in D .
$$

Many authors have studied the problems of finding a common element of the set of fixed points of a nonexpansive mapping and one of the sets of solutions to the variational inclusion and variational inequalities (1.15)-(1.17) and (1.21) by using different iterative methods (see, e.g., [10, 16-27]). 
Recently, Qin et al. [8] considered the problem of finding the solutions of a general system of variational inclusion (1.15) with $\alpha$-inverse strongly accretive mappings. To be more precise, they obtained the following results.

Lemma 1.11. For any $\left(x^{*}, y^{*}\right) \in X \times X$, where $y^{*}=J_{\left(M_{2}, \rho_{2}\right)}\left(x^{*}-\rho_{2} B_{2} x^{*}\right),\left(x^{*}, y^{*}\right)$ is a solution of the problem (1.15) if and only if $x^{*}$ is a fixed point of the mapping $Q$ defined by

$$
Q x:=J_{\left(M_{1}, \rho_{1}\right)}\left[J_{\left(M_{2}, \rho_{2}\right)}\left(x-\rho_{2} B_{2} x\right)-\rho_{1} B_{1} J_{\left(M_{2}, \rho_{2}\right)}\left(x-\rho_{2} B_{2} x\right)\right] .
$$

Theorem QCCK 1.12 (see [8]). Let X be a uniformly convex and 2-uniformly smooth Banach space with the smoothness constant $K$. Let $M_{i}: X \rightarrow 2^{X}$ be a maximal monotone mapping and $B_{i}: X \rightarrow$ $X$ be a $\rho_{i}$-inverse-strongly accretive mapping, respectively, for all $i=1,2$. Let $T: X \rightarrow X$ be a $\epsilon$-strict pseudocontraction such that $F(T) \neq \emptyset$. Define a mapping $S$ by $S x=\left(1-\epsilon / K^{2}\right) x+\left(\epsilon / K^{2}\right) T x$, for all $x \in X$. Assume that $\Omega=F(T) \cap F(Q)$, where $Q$ is defined as in Lemma 1.11. Let $x_{1}=u \in C$ and let $\left\{x_{n}\right\}$ be a sequence defined by

$$
\begin{gathered}
z_{n}=J_{\left(M_{2}, \rho_{2}\right)}\left(x_{n}-\rho_{2} B_{2} x_{n}\right), \\
y_{n}=J_{\left(M_{1}, \rho_{1}\right)}\left(z_{n}-\rho_{1} B_{1} z_{n}\right), \\
x_{n+1}=\alpha_{n} u+\beta_{n} x_{n}+\left(1-\beta_{n}-\alpha_{n}\right)\left[\mu S x_{n}+(1-\mu) y_{n}\right], \quad \forall n \geq 1,
\end{gathered}
$$

where $\mu \in(0,1), \rho_{1} \in\left(0, \gamma_{1} / K^{2}\right], \rho_{2} \in\left(0, \gamma_{2} / K^{2}\right]$, and $\left\{\alpha_{n}\right\},\left\{\beta_{n}\right\}$ are sequences in $(0,1)$. If the control consequences $\left\{\alpha_{n}\right\}$ and $\left\{\beta_{n}\right\}$ satisfy the following restrictions:

(C1) $0<\lim \inf _{n \rightarrow \infty} \beta_{n} \leq \lim \sup _{n \rightarrow \infty} \beta_{n}<1$,

(C2) $\lim _{n \rightarrow \infty} \alpha_{n}=0$ and $\sum_{n=1}^{\infty} \alpha_{n}=\infty$,

then $\left\{x_{n}\right\}$ converges strongly to $x^{*}=P_{\Omega} u$, where $P_{\Omega}$ is the sunny nonexpansive retraction from $X$ onto $\Omega$ and $\left(x^{*}, y^{*}\right)$ is a solution of the problem (1.15), where $y^{*}=J_{\left(M_{2}, \rho_{2}\right)}\left(x^{*}-\rho_{2} B_{2} x^{*}\right)$.

Iterative methods for nonexpansive mappings have recently been applied to solve minimization problems; see, for example, [28-32]. Let $H$ be a real Hilbert space, whose inner product and norm are denoted by $\|\cdot, \cdot\|$ and $\langle\cdot\rangle$, respectively. Let $A$ be a strongly positive bounded linear operator on $H$ : that is, there is a constant $\gamma>0$ with property

$$
\langle A x, x\rangle \geq \bar{\gamma}\|x\|^{2}, \quad \forall x \in H .
$$

A typical problem is to minimize a quadratic function over the set of the fixed points of a nonexpansive mapping on a real Hilbert space $H$

$$
\min _{x \in F} \frac{1}{2}\langle A x, x\rangle-\langle x, u\rangle
$$

where $F$ is the fixed point set of a nonexpansive mapping $T$ on $H$ and $u$ is a given point in $H$. 
In [33], Moudafi introduced the viscosity approximation method and proved that if $H$ is a real Hilbert space, the sequence $\left\{x_{n}\right\}$ generated by the following algorithm:

$$
\begin{gathered}
x_{0}=u \in H \text { chosen arbitrarily, } \\
x_{n+1}=\alpha_{n} f\left(x_{n}\right)+\left(1-\alpha_{n}\right) T x_{n}, \quad \forall n \geq 0,
\end{gathered}
$$

where $f: C \rightarrow C$ is a contraction mapping with a constant $\alpha \in(0,1)$ and $\left\{\alpha_{n}\right\} \subset(0,1)$ satisfies certain conditions, converges strongly to a fixed point of $T$ in $C$ which is the unique solution of the following variational inequality:

$$
\left\langle(f-I) x^{*}, x-x^{*}\right\rangle \leq 0, \quad \forall x \in F(T) .
$$

In 2006, Marino and Xu [34] introduced the following general iterative method:

$$
\begin{gathered}
x_{0}=u \in H \text { chosen arbitrarily, } \\
x_{n+1}=\alpha_{n} \gamma f\left(x_{n}\right)+\left(I-\alpha_{n} A\right) T x_{n}, \quad \forall n \geq 0,
\end{gathered}
$$

where $A$ is a strongly positive bounded linear operator on a Hilbert space $H$. They proved that, if the sequence $\left\{\alpha_{n}\right\}$ of parameters satisfies appropriate conditions, then the sequence $\left\{x_{n}\right\}$ generated by (1.32) converges strongly to the unique solution of the variational inequality:

$$
\left\langle(\gamma f-A) x^{*}, x-x^{*}\right\rangle \leq 0, \quad \forall x \in F(T)
$$

which is the optimality condition for the minimization problem:

$$
\min _{x \in C} \frac{1}{2}\langle A x, x\rangle-h(x)
$$

where $C$ is the fixed point set of a nonexpansive mapping $T$ and $h$ is a potential function for $\gamma f$ (i.e., $h^{\prime}(x)=\gamma f(x)$ for all $x \in H$ ).

In a smooth Banach space, we always assume that $A$ is strongly positive (see [35]), that is, a constant $\bar{\gamma}>0$ with the property

$$
\langle A x, J(x)\rangle \geq \bar{r}\|x\|^{2}, \quad\|a I-b A\|=\sup _{\|x\| \leq 1}|\langle(a I-b A) x, J(x)\rangle|, \quad a \in[0,1], b \in[-1,1],
$$

where $I$ is the identity mapping and $J$ is the normalized duality mapping.

Recently, Sunthrayuth and Kumam [36] introduced the following iterative method for nonexpansive semigroup $\mathcal{S}=\left\{T(t): t \in \mathbb{R}^{+}\right\}$in Banach spaces,

$$
\begin{gathered}
x_{0}=u \in C \text { chosen arbitrarily, } \\
x_{n+1}=\alpha_{n} \gamma f\left(x_{n}\right)+\beta_{n} x_{n}+\left(\left(1-\beta_{n}\right) I-\alpha_{n} A\right) \frac{1}{t_{n}} \int_{0}^{t_{n}} T(s) x_{n} d s, \quad \forall n \geq 0 .
\end{gathered}
$$


They proved strong convergence theorem of the iterative scheme $\left\{x_{n}\right\}$ defined by (1.36) converges strongly to the common fixed point of $x^{*} \in F(\mathcal{S})$ solving the variational inequality

$$
\left\langle(\gamma f-A) x^{*}, J\left(x-x^{*}\right)\right\rangle \leq 0, \quad \forall x \in F(\mathcal{S}) .
$$

In 2010, Kamraksa and Wangkeeree [37] introduced a general iterative approximation method for finding common elements of the set of solutions to a general system of variational inclusions with Lipschitzian and relaxed cocoercive mappings and the set common fixed points of a countable family of strict pseudocontractions. They proved the strong convergence theorems of such iterative scheme for finding a common element of such two sets which is a unique solution of some variational inequality and is also the optimality condition for some minimization problems in a strictly convex and 2-uniformly smooth Banach space.

In this paper, we are motivated and inspire by idea of Qin et al. [8] and Sunthrayuth and Kumam [36]. follows.

First, we introduce a new general system of variational inclusions in Banach spaces as

Let $X$ be Banach spaces. We consider a system of quasivariational inclusions as follows. Finding $\left(x^{*}, y^{*}, z^{*}\right) \in X \times X \times X$ such that

$$
\begin{aligned}
& 0 \in x^{*}-y^{*}+\rho_{1}\left(B_{1} y^{*}+M_{1} x^{*}\right) \\
& 0 \in y^{*}-z^{*}+\rho_{2}\left(B_{2} z^{*}+M_{2} y^{*}\right) \\
& 0 \in z^{*}-x^{*}+\rho_{3}\left(B_{3} x^{*}+M_{3} z^{*}\right)
\end{aligned}
$$

which is called a new general system of variational inclusions in Banach spaces, $B_{i}: X \rightarrow X$ and $M_{i}: X \rightarrow 2^{X}$ are nonlinear mappings for all $i=1,2,3$. As special cases of problem (1.38), we have the following.

(1) If $B_{1}=B_{2}=B_{3}=B$ and $M_{1}=M_{2}=M_{3}=M$, then problem (1.38) is reduced to the following. Finding $\left(x^{*}, y^{*}, z^{*}\right) \in X \times X \times X$ such that

$$
\begin{aligned}
& 0 \in x^{*}-y^{*}+\rho_{1}\left(B y^{*}+M x^{*}\right), \\
& 0 \in y^{*}-z^{*}+\rho_{2}\left(B z^{*}+M y^{*}\right), \\
& 0 \in z^{*}-x^{*}+\rho_{3}\left(B x^{*}+M z^{*}\right) .
\end{aligned}
$$

(2) Further, if $B_{3}=M_{3}=0, z^{*}=x^{*}$, then problem (1.38) is reduced to problem (1.15).

Second, we study a general iterative approximation method (3.1) below, for finding common elements of the set of solutions of a new general system of variational inclusions (1.38) with set-valued maximal monotone mapping and Lipschitzian relaxed cocoercive mappings and the set common fixed points of nonexpansive semigroup in the framework of Banach spaces. Moreover, we prove the strong convergence of the proposed iterative method under some certain control conditions. The results presented in this paper extend and improve the results of Qin et al. [8] and Sunthrayuth and Kumam [36], and many authors. 


\section{Preliminaries}

This section collects some results that will be used in the proofs of our main results.

Lemma 2.1 (see [38]). The resolvent operator $J_{(M, \rho)}$ associated with $M$ is single valued and nonexpansive for all $\rho>0$.

Lemma 2.2 (see [39]). Let X be a real 2-uniformly smooth Banach space with the best smoothness constant $K$. Then, the following inequality holds:

$$
\|x+y\|^{2} \leq\|x\|^{2}+2\langle y, J x\rangle+2\|K y\|^{2}, \quad \forall x, y \in X
$$

Lemma 2.3 (see [40]). In a real Banach space X, the following inequality holds:

$$
\|x+y\|^{2} \leq\|x\|^{2}+2\langle y, J(x+y)\rangle, \quad \forall x, y \in X
$$

Now, we present the concept of a uniformly asymptotically regular semigroup (see [41-43]).

Definition 2.4. Let $C$ be a nonempty closed convex subset of a Banach space $X, S=\{T(t): t \in$ $\left.\mathbb{R}^{+}\right\}$be a continuous operator semigroup on $C$. Then $S$ is said to be uniformly asymptotically regular (in short, u.a.r.) on $C$ if for all $h \geq 0$ and any bounded subset $B$ of $C$ such that

$$
\lim _{t \rightarrow \infty} \sup _{x \in B}\|T(h) T(t) x-T(t) x\|=0 .
$$

Lemma 2.5 (see [44]). Let $C$ be a nonempty closed convex subset of a uniformly Banach space $X, B$ be a bounded closed convex subset of $C$. If we denote $\mathcal{S}=\left\{T(t): t \in \mathbb{R}^{+}\right\}$a nonexpansive semigroup on $C$ such that $F(\mathcal{S}):=\bigcap_{t \in \mathbb{R}^{+}} F(T(t)) \neq \emptyset$. For all $h \geq 0$, the set $\sigma_{t}(x)=(1 / t) \int_{0}^{t} T(s) x d s$, then

$$
\lim _{t \rightarrow \infty} \sup _{x \in B}\left\|\sigma_{t}(x)-T(h) \sigma_{t}(x)\right\|=0 .
$$

Remark 2.6. It is easy to check that the set $\left\{\sigma_{t}: t \in \mathbb{R}^{+}\right\}$defined by Lemma 2.5 is a u.a.r. nonexpansive semigroup on $C$ (see [45] for more detail).

Lemma 2.7 (see [46]). Let $C$ be a nonempty closed convex subset of $X$ and let $\mathcal{S}=\left\{T(t): t \in \mathbb{R}^{+}\right\}$be a u.a.r. nonexpansive semigroup on $C$ such $F(S):=\bigcap_{t \in \mathbb{R}^{+}} F(T(t)) \neq \emptyset$ and at least there exists a $T(t)$ which is demicompact. Then, for each $x \in C$, there exists a sequence $\left\{T\left(t_{n}\right): t_{n} \in \mathbb{R}^{+}, n \in \mathbb{N}\right\} \subset T(t)$, such that $\left\{T\left(t_{n}\right) x\right\}$ converges strongly to some point in $F(\mathcal{S})$, where $\lim _{n \rightarrow \infty} t_{n}=\infty$.

Remark 2.8. By Lemma 2.7, we can see that, for each $x \in C$, there is a corresponding unique point $y \in F(\mathcal{S})$, thus we can define a mapping $T$ such that $T x=y$ and it is easy to see that $F(T)=F(\mathcal{S})$.

Remark 2.9. From the definition of $T$, we can see that $T$ is a nonexpansive mapping. Actually, by Lemma 2.7, let $x_{1} \in C$; then there exists a sequence $\left\{T\left(t_{n}\right)\right\}$ of $\{T(h)\}$ such that 
$T x_{1}=\lim _{n \rightarrow \infty} T\left(t_{n}\right) x_{1}=y_{1} \in F(\mathcal{S})$. Further, for any other point $x_{2} \in C$, by the definition of a u.a.r., we can get a subsequence $\left\{T\left(t_{n_{k}}\right)\right\}$ of $\left\{T\left(t_{n}\right)\right\}$ such that $T\left(t_{n_{k}}\right) \rightarrow y_{2} \in F(\mathcal{S})$, then

$$
\left\|T x_{1}-T x_{2}\right\|=\lim _{k \rightarrow \infty}\left\|T\left(t_{n_{k}}\right) x_{1}-T\left(t_{n_{k}}\right) x_{2}\right\| \leq\left\|x_{1}-x_{2}\right\| .
$$

Lemma 2.10 (see [35]). Let $C$ be a nonempty closed convex subset of a reflexive, smooth Banach space $X$ which admits a weakly sequentially continuous duality mapping $J$ from $X$ into $X^{*}, T$ be a nonexpansive mapping such that $F(T) \neq \emptyset, f: C \rightarrow C$ be a contraction mapping with a coefficient $\alpha \in(0,1)$ and $A$ be a strongly positive bounded linear operator with a coefficient $\bar{\gamma}>0$. Let $t \in(0,1)$ such that $t \leq\|A\|^{-1}$ and $0<\gamma<\bar{\gamma} / \alpha$ which satisfies $t \rightarrow 0$. Then the sequence $\left\{x_{t}\right\}$ defined by

$$
x_{t}=\operatorname{tr} f\left(x_{t}\right)+(I-t A) T x_{t},
$$

converges strongly to the common fixed point $x^{*}$ as $t \rightarrow 0$, where $x^{*}$ is a unique solution in $F(\mathcal{S})$ of the variational inequality

$$
\left\langle(\gamma f-A) x^{*}, J\left(z-x^{*}\right)\right\rangle \leq 0, \quad \forall z \in F(\mathcal{S}) .
$$

Lemma 2.11 (see [47]). Let $C$ be a closed convex subset of a strictly convex Banach space X. Let $\left\{T_{n}: n \in \mathbb{N}\right\}$ be a sequence of nonexpansive mappings on $C$. Suppose $\bigcap_{n=1}^{\infty} F\left(T_{n}\right)$ is nonempty. Let $\left\{\mu_{n}\right\}$ be a sequence of positive numbers with $\sum_{n=1}^{\infty} \mu_{n}=1$. Then a mapping $S$ on $C$ defined by $S x=\sum_{n=1}^{\infty} \mu_{n} T_{n} x$ for all $x \in C$ is well defined, nonexpansive and $F(S)=\bigcap_{n=1}^{\infty} F\left(T_{n}\right)$ holds.

Lemma 2.12 (see [48]). Let $\left\{x_{n}\right\}$ and $\left\{v_{n}\right\}$ be bounded sequences in a Banach space $X$ and let $\left\{\beta_{n}\right\}$ be a sequence in $[0,1]$ with $0<\lim _{\inf _{n \rightarrow \infty}} \beta_{n} \leq \lim \sup _{n \rightarrow \infty} \beta_{n}<1$. Suppose $x_{n+1}=\left(1-\beta_{n}\right) v_{n}+\beta_{n} x_{n}$ for all integers $n \geq 0$ and $\lim \sup _{n \rightarrow \infty}\left(\left\|v_{n+1}-v_{n}\right\|-\left\|x_{n+1}-x_{n}\right\|\right) \leq 0$. Then, $\lim _{n \rightarrow \infty}\left\|v_{n}-x_{n}\right\|=0$.

Lemma 2.13 (see [35]). Assume that $A$ is a strongly positive linear bounded operator on a smooth Banach space $X$ with coefficient $\bar{\gamma}>0$ and $0<\rho \leq\|A\|^{-1}$. Then $\|I-\rho A\| \leq 1-\rho \bar{\gamma}$.

If a Banach space $X$ admits a sequentially continuous duality mapping $J$ from weak topology to weak star topology, then by Lemma 1 of [49], we have that duality mapping $J$ is a single value. In this case, the duality mapping $J$ is said to be a weakly sequentially continuous duality mapping, that is, for each $\left\{x_{n}\right\} \subset X$ with $x_{n} \rightarrow x$, we have $J\left(x_{n}\right)-^{*} J(x)$ (see [49-51] for more details).

A Banach space $X$ is said to be satisfying Opial's condition if for any sequence $x_{n} \rightarrow x$ for all $x \in X$ implies

$$
\limsup _{n \rightarrow \infty}\left\|x_{n}-x\right\|<\limsup _{n \rightarrow \infty}\left\|x_{n}-y\right\|, \quad \forall y \in X, \text { with } x \neq y .
$$

By Theorem 1 in [49], it is well known that if $X$ admits a weakly sequentially continuous duality mapping, then $X$ satisfies Opial's condition, and $X$ is smooth.

Lemma 2.14 (see [50], Demiclosed principle). Let $C$ be a nonempty closed convex subset of a reflexive Banach space $X$ which satisfies Opial's condition and suppose $T: C \rightarrow X$ is nonexpansive. Then the mapping $I-T$ is demiclosed at zero, that is, $x_{n} \rightarrow x$ and $x_{n}-T x_{n} \rightarrow 0$ implies $x=T x$. 
Lemma 2.15 (see [30]). Assume that $\left\{a_{n}\right\}$ is a sequence of nonnegative real numbers such that

$$
a_{n+1} \leq\left(1-\tau_{n}\right) a_{n}+\sigma_{n}
$$

where $\left\{\tau_{n}\right\}$ is a sequence in $(0,1)$ and $\left\{\sigma_{n}\right\}$ is a sequence in $\mathbb{R}$ such that

(i) $\sum_{n=0}^{\infty} \tau_{n}=\infty$,

(ii) $\lim \sup _{n \rightarrow \infty}\left(\sigma_{n} / \tau_{n}\right) \leq 0$ or $\sum_{n=0}^{\infty}\left|\sigma_{n}\right|<\infty$.

Then, $\lim _{n \rightarrow \infty} a_{n}=0$.

Let $X$ be a real 2-uniformly smooth Banach space $X$ with the smoothness constant $K$. Let $B: X \rightarrow X$ be an $L_{B}$-Lipschitzian and relaxed $(c, d)$-cocoercive mapping, we defined a function $p:(0,+\infty) \rightarrow(-\infty,+\infty)$ by

$$
p(\rho):=1+2 \rho c L_{B}^{2}-2 \rho d+2 \rho^{2} K^{2} L_{B^{\prime}}^{2} \quad \forall \rho \in(0,+\infty) .
$$

Consequence, we put

$$
\theta_{\rho}= \begin{cases}\sqrt{p(\rho)}, & \text { if } p(\rho)>0 \\ \frac{1}{1+K^{\prime}}, & \text { if } p(\rho) \leq 0\end{cases}
$$

In order to prove our main result, the following lemmas are needed.

Lemma 2.16. Let $X$ be a real 2-uniformly smooth Banach space $X$ with the smoothness constant $K$. Let $B: X \rightarrow X$ be an $L_{B}$-Lipschitzian and relaxed $(c, d)$-cocoercive mapping. Then

$$
\|(I-\rho B) x-(I-\rho B) y\|^{2} \leq \theta_{\rho}^{2}\|x-y\|^{2} .
$$

In particular, if $0<\rho \leq\left(d-c L_{B}^{2}\right) / K^{2} L_{B}^{2}$, then $I-\rho B$ is nonexpansive.

Proof. For all $x, y \in X$, from Lemma 2.2 and by the cocoercivity of the mapping $B$, we have

$$
\begin{aligned}
\|(I-\rho B) x-(I-\rho B) y\|^{2} & =\|(x-y)-(\rho B x-\rho B y)\|^{2} \\
& \leq\|x-y\|^{2}-2 \rho\langle B x-B y, J(x-y)\rangle+2 \rho^{2} K^{2}\|B x-B y\|^{2} \\
& \leq\|x-y\|^{2}-2 \rho\left[-c\|B x-B y\|^{2}+d\|x-y\|^{2}\right]+2 \rho^{2} K^{2}\|B x-B y\|^{2} \\
& =\|x-y\|^{2}-2 \rho d\|x-y\|^{2}+2 \rho c\|B x-B y\|^{2}+2 \rho^{2} K^{2}\|B x-B y\|^{2} \\
& \leq\left(1+2 \rho c L_{B}^{2}-2 \rho d+2 \rho^{2} K^{2} L_{B}^{2}\right)\|x-y\|^{2} \\
& =\theta_{\rho}^{2}\|x-y\|^{2} .
\end{aligned}
$$


It follows that

$$
\|(I-\rho B) x-(I-\rho B) y\| \leq \theta_{\rho}\|x-y\| .
$$

It is clear that, if $0<\rho \leq\left(d-c L_{B}^{2}\right) / K^{2} L_{B}^{2}$. Thus, we have $I-\rho B$ is nonexpansive.

Lemma 2.17. Let $X$ be a 2-uniformly smooth Banach space $X$. Let $M_{i}: X \rightarrow 2^{X}$ be the a maximal monotone mapping and $B_{i}: X \rightarrow X$ be an $L_{i}$-Lipschitzian and relaxed $\left(c_{i}, d_{i}\right)$-cocoercive mapping for $i=1,2,3$. Let $Q: X \rightarrow X$ be a mapping defined by

$$
\begin{aligned}
Q x:=J_{\left(M_{1}, \rho_{1}\right)}( & J_{\left(M_{2}, \rho_{2}\right)}\left(J_{\left(M_{3}, \rho_{3}\right)}\left(x-\rho_{3} B_{3} x\right)-\rho_{2} B_{2} J_{\left(M_{3}, \rho_{3}\right)}\left(x-\rho_{3} B_{3} x\right)\right. \\
& \left.\left.-\rho_{1} B_{1} J_{\left(M_{2}, \rho_{2}\right)} J_{\left(M_{3}, \rho_{3}\right)}\left(x-\rho_{3} B_{3} x\right)-\rho_{2} B_{2} J_{\left(M_{3}, \rho_{3}\right)}\left(x-\rho_{3} B_{3} x\right)\right)\right), \quad \forall x \in X .
\end{aligned}
$$

If $0<\rho_{i} \leq\left(d_{i}-c_{i} L_{i}^{2}\right) / K^{2} L_{i}^{2}$ and $\theta_{\rho}=\max \left\{\theta_{\rho_{i}}\right\}$ for all $i=1,2,3$, then the mapping $Q$ is nonexpansive.

Proof. For all $x, y \in X$, we have

$$
\begin{gathered}
\|Q x-Q y\| \leq \| J_{\left(M_{1}, \rho_{1}\right)}\left[J_{\left(M_{2}, \rho_{2}\right)}\left(J_{\left(M_{3}, \rho_{3}\right)}\left(x-\rho_{3} B_{3} x\right)-\rho_{2} B_{2} J_{\left(M_{3}, \rho_{3}\right)}\left(x-\rho_{3} B_{3} x\right)\right)\right. \\
\left.-\rho_{1} B_{1} J_{\left(M_{2}, \rho_{2}\right)}\left(J_{\left(M_{3}, \rho_{3}\right)}\left(x-\rho_{3} B_{3} x\right)-\rho_{2} B_{2} J_{\left(M_{3}, \rho_{3}\right)}\left(x-\rho_{3} B_{3} x\right)\right)\right] \\
-J_{\left(M_{1}, \rho_{1}\right)}\left[J_{\left(M_{2}, \rho_{2}\right)}\left(J_{\left(M_{3}, \rho_{3}\right)}\left(y-\rho_{3} B_{3} y\right)-\rho_{2} B_{2} J_{\left(M_{3}, \rho_{3}\right)}\left(y-\rho_{3} B_{3} y\right)\right)\right. \\
\left.\quad-\rho_{1} B_{1} J_{\left(M_{2}, \rho_{2}\right)}\left(J_{\left(M_{3}, \rho_{3}\right)}\left(y-\rho_{3} B_{3} y\right)-\rho_{2} B_{2} J_{\left(M_{3}, \rho_{3}\right)}\left(y-\rho_{3} B_{3} y\right)\right)\right] \| \\
\leq \| J_{\left(M_{2}, \rho_{2}\right)}\left(J_{\left(M_{3}, \rho_{3}\right)}\left(x-\rho_{3} B_{3} x\right)-\rho_{2} B_{2} J_{\left(M_{3}, \rho_{3}\right)}\left(x-\rho_{3} B_{3} x\right)\right) \\
\quad-\rho_{1} B_{1} J_{\left(M_{2}, \rho_{2}\right)}\left(J_{\left(M_{3}, \rho_{3}\right)}\left(x-\rho_{3} B_{3} x\right)-\rho_{2} B_{2} J_{\left(M_{3}, \rho_{3}\right)}\left(x-\rho_{3} B_{3} x\right)\right) \\
\quad-J_{\left(M_{2}, \rho_{2}\right)}\left(J_{\left(M_{3}, \rho_{3}\right)}\left(y-\rho_{3} B_{3} y\right)-\rho_{2} B_{2} J_{\left(M_{3}, \rho_{3}\right)}\left(y-\rho_{3} B_{3} y\right)\right) \\
\quad-\rho_{1} B_{1} J_{\left(M_{2}, \rho_{2}\right)}\left(J_{\left(M_{3}, \rho_{3}\right)}\left(y-\rho_{3} B_{3} y\right)-\rho_{2} B_{2} J_{\left(M_{3}, \rho_{3}\right)}\left(y-\rho_{3} B_{3} y\right)\right) \| \\
=\| J_{\left(M_{2}, \rho_{2}\right)}\left(I-\rho_{2} B_{2}\right) J_{\left(M_{3}, \rho_{3}\right)}\left(I-\rho_{3} B_{3}\right)\left(I-\rho_{1} B_{1}\right) x \\
\quad-J_{\left(M_{2}, \rho_{2}\right)}\left(I-\rho_{2} B_{2}\right) J_{\left(M_{3}, \rho_{3}\right)}\left(I-\rho_{3} B_{3}\right)\left(I-\rho_{1} B_{1}\right) y \| \\
\leq \|\left(I-\rho_{2} B_{2}\right) J_{\left(M_{3}, \rho_{3}\right)}\left(I-\rho_{3} B_{3}\right)\left(I-\rho_{1} B_{1}\right) x \\
\quad-\left(I-\rho_{2} B_{2}\right) J_{\left(M_{3}, \rho_{3}\right)}\left(I-\rho_{3} B_{3}\right)\left(I-\rho_{1} B_{1}\right) y \| .
\end{gathered}
$$

From Lemma 2.16 and by the nonexpansiveness of $J_{\left(M_{i}, \rho_{i}\right)}$ for all $i=1,2,3$, we have $(I-$ $\left.\rho_{2} B_{2}\right) J_{\left(M_{3}, \rho_{3}\right)}\left(I-\rho_{3} B_{3}\right)\left(I-\rho_{1} B_{1}\right)$ is a nonexpansive mapping, which implies that the mapping $Q$ is nonexpansive. 
Lemma 2.18. For all $\left(x^{*}, y^{*}, z^{*}\right) \in X \times X \times X$, where $y^{*}=J_{\left(M_{2}, \rho_{2}\right)}\left(z^{*}-\rho_{2} B_{2} z^{*}\right)$ and $z^{*}=J_{\left(M_{3}, \rho_{3}\right)}\left(x^{*}-\right.$ $\left.\rho_{3} B_{3} x^{*}\right),\left(x^{*}, y^{*}, z^{*}\right)$ is a solution of the problem (1.38) if and only if $x^{*}$ is a fixed point of the mapping $Q$ defined as in Lemma 2.17 .

Proof. Let $\left(x^{*}, y^{*}, z^{*}\right) \in X \times X \times X$ be a solution of the problem (1.38). Then, we have

$$
\begin{aligned}
& y^{*}-\rho_{1} B_{1} y^{*} \in\left(I+\rho_{1} M_{1}\right) x^{*}, \\
& z^{*}-\rho_{2} B_{2} z^{*} \in\left(I+\rho_{2} M_{2}\right) y^{*}, \\
& x^{*}-\rho_{3} B_{3} x^{*} \in\left(I+\rho_{3} M_{3}\right) z^{*},
\end{aligned}
$$

which implies that

$$
\begin{aligned}
& x^{*}=J_{\left(M_{1}, \rho_{1}\right)}\left(y^{*}-\rho_{1} B_{1} y^{*}\right), \\
& y^{*}=J_{\left(M_{2}, \rho_{2}\right)}\left(z^{*}-\rho_{2} B_{2} z^{*}\right), \\
& z^{*}=J_{\left(M_{3}, \rho_{3}\right)}\left(x^{*}-\rho_{3} B_{3} x^{*}\right) .
\end{aligned}
$$

We can deduce that (2.18) is equivalent to

$$
\begin{aligned}
x^{*}=J_{\left(M_{1}, \rho_{1}\right)}\left[J_{\left(M_{2}, \rho_{2}\right)}(\right. & J_{\left(M_{3}, \rho_{3}\right)}\left(x^{*}-\rho_{3} B_{3} x^{*}\right)-\rho_{2} B_{2} J_{\left(M_{3}, \rho_{3}\right)}\left(x^{*}-\rho_{3} B_{3} x^{*}\right) \\
& \left.\left.-\rho_{1} B_{1} J_{\left(M_{2}, \rho_{2}\right)} J_{\left(M_{3}, \rho_{3}\right)}\left(x^{*}-\rho_{3} B_{3} x^{*}\right)-\rho_{2} B_{2} J_{\left(M_{3}, \rho_{3}\right)}\left(x^{*}-\rho_{3} B_{3} x^{*}\right)\right)\right] .
\end{aligned}
$$

This completes the proof.

\section{Main Results}

In this section, we prove that the iterative scheme (3.1) below converges strongly to common element of the set of solutions of the variational inclusion with set-valued maximal monotone mapping and Lipschitzian relaxed cocoercive mapping and the set of fixed point of a family of nonexpansive semigroup in a uniformly convex and 2-uniformly smooth Banach space under some certain control conditions.

Now, we prove the strong convergence theorem of the sequence (3.1) for solving the problem (1.38).

Theorem 3.1. Let $X$ be a uniformly convex and 2-uniformly smooth Banach space which admits a weakly continuous duality mapping and has the smoothness constant $K$. Let $M_{i}: X \rightarrow 2^{X}$ be a maximal monotone mapping and $B_{i}: X \rightarrow X$ be a $L_{i}$-Lipschitzian and relaxed $\left(c_{i}, d_{i}\right)$-cocoercive mapping with $\rho_{i} \in\left(0,\left(d_{i}-c_{i} L_{i}^{2}\right) / K^{2} L_{i}^{2}\right]$ and $\theta_{\rho}=\max \left\{\theta_{\rho_{i}}\right\}$ for all $i=1,2,3$. Let $\mathcal{S}=\{T(t)$ : $\left.t \in \mathbb{R}^{+}\right\}$be a nonexpansive semigroup from $X$ into itself and at least there exists a $T(t)$ which is demicompact. Assume that $\Omega:=F(\mathcal{S}) \cap F(Q) \neq \emptyset$, where $Q$ is defined as in Lemma 2.17. Let $f: X \rightarrow$ $X$ be a contraction mapping with a coefficient $\alpha \in(0,1)$ and $A$ be a strongly positive linear bounded 
self adjoint operator with a coefficient $\bar{\gamma} \in(0,1)$ such that $\|A\| \leq 1$ and $0<\gamma<\bar{\gamma} / \alpha$. Let $\left\{x_{n}\right\}$ be a sequence defined by

$$
\begin{gathered}
x_{1} \in X \text { chosen arbitrarily, } \\
z_{n}=J_{\left(M_{3}, \rho_{3}\right)}\left(x_{n}-\rho_{3} B_{3} x_{n}\right), \\
y_{n}=J_{\left(M_{2}, \rho_{2}\right)}\left(z_{n}-\rho_{2} B_{2} z_{n}\right), \\
v_{n}=J_{\left(M_{1}, \rho_{1}\right)}\left(y_{n}-\rho_{1} B_{1} y_{n}\right), \\
x_{n+1}=\alpha_{n} \gamma f\left(x_{n}\right)+\beta_{n} x_{n}+\left(\left(1-\beta_{n}\right) I-\alpha_{n} A\right)\left[\mu \frac{1}{t_{n}} \int_{0}^{t_{n}} T(s) x_{n} d s+(1-\mu) v_{n}\right], \quad \forall n \geq 1,
\end{gathered}
$$

where $\mu \in(0,1),\left\{\alpha_{n}\right\}_{n=1}^{\infty},\left\{\beta_{n}\right\}_{n=1}^{\infty}$ are the sequences in $(0,1)$ which satisfies $\alpha_{n}+\beta_{n} \leq 1$ and $\left\{t_{n}\right\}_{n=1}^{\infty}$ is a positive real divergent sequence satisfy the following restrictions:

(C1) $\lim _{n \rightarrow \infty} \alpha_{n}=0$ and $\sum_{n=1}^{\infty} \alpha_{n}=\infty$,

(C2) $0<\lim \inf _{n \rightarrow \infty} \beta_{n} \leq \lim \sup _{n \rightarrow \infty} \beta_{n}<1$,

(C3) $\lim _{n \rightarrow \infty}\left|t_{n+1}-t_{n}\right| / t_{n+1}=0$.

Then the sequence $\left\{x_{n}\right\}$ defined by (3.1) converges strongly to $x^{*}$, which $x^{*}$ solves the variational inequality

$$
\left\langle(\gamma f-A) x^{*}, J\left(z-x^{*}\right)\right\rangle \leq 0, \quad \forall z \in \Omega,
$$

and $\left(x^{*}, y^{*}, z^{*}\right)$ is a solution of general system of variational inequality problem (1.38), where $y^{*}=$ $J_{\left(M_{2}, \rho_{2}\right)}\left(z^{*}-\rho_{2} B_{2} z^{*}\right)$ and $z^{*}=J_{\left(M_{3}, \rho_{3}\right)}\left(x^{*}-\rho_{3} B_{3} x^{*}\right)$.

Proof. First, we show $\left\{x_{n}\right\}$ is bounded. By the condition (C1), we may assume, with no loss of generality, that $\alpha_{n} \leq\left(1-\beta_{n}\right)\|A\|^{-1}$. Since $A$ is a linear bounded operator on $X$, by (1.35), we have $\|A\|=\sup \{|\langle A u, J(u)\rangle|: u \in X,\|u\|=1\}$. Observe that

$$
\begin{aligned}
\left\langle\left(\left(1-\beta_{n}\right) I-\alpha_{n} A\right) u, J(u)\right\rangle & =1-\beta_{n}-\alpha_{n}\langle A u, J(u)\rangle \\
& \geq 1-\beta_{n}-\alpha_{n}\|A\| \\
& \geq 0
\end{aligned}
$$

that is, $\left(1-\beta_{n}\right) I-\alpha_{n} A$ is positive. It follows that

$$
\begin{aligned}
\left\|\left(1-\beta_{n}\right) I-\alpha_{n} A\right\| & =\sup \left\{\left\langle\left(\left(1-\beta_{n}\right) I-\alpha_{n} A\right) u, J(u)\right\rangle: u \in X,\|u\|=1\right\} \\
& =\sup \left\{1-\beta_{n}-\alpha_{n}\langle A u, J(u)\rangle: u \in X,\|u\|=1\right\} \\
& \leq 1-\beta_{n}-\alpha_{n} \bar{\gamma} .
\end{aligned}
$$


Taking $\bar{x} \in \Omega$, it follows from Lemma 2.17 that

$$
\begin{aligned}
\bar{x}=J_{\left(M_{1}, \rho_{1}\right)}\left[J_{\left(M_{2}, \rho_{2}\right)}\right. & \left(J_{\left(M_{3}, \rho_{3}\right)}\left(\bar{x}-\rho_{3} B_{3} \bar{x}\right)-\rho_{2} B_{2} J_{\left(M_{3}, \rho_{3}\right)}\left(\bar{x}-\rho_{3} B_{3} \bar{x}\right)\right. \\
& \left.\left.-\rho_{1} B_{1} J_{\left(M_{2}, \rho_{2}\right)} J_{\left(M_{3}, \rho_{3}\right)}\left(\bar{x}-\rho_{3} B_{3} \bar{x}\right)-\rho_{2} B_{2} J_{\left(M_{3}, \rho_{3}\right)}\left(\bar{x}-\rho_{3} B_{3} \bar{x}\right)\right)\right] .
\end{aligned}
$$

Putting $\bar{y}=J_{\left(M_{2}, \rho_{2}\right)}\left(\bar{z}-\rho_{2} B_{2} \bar{z}\right)$ and $\bar{z}=J_{\left(M_{1}, \rho_{1}\right)}\left(\bar{x}-\rho_{3} B_{3} \bar{x}\right)$. Then $\bar{x}=J_{\left(M_{1}, \rho_{1}\right)}\left(\bar{y}-\rho_{1} B_{1} \bar{y}\right)$. It follows from Lemmas 2.1 and 2.16 that

$$
\begin{aligned}
\left\|v_{n}-\bar{x}\right\| & =\left\|J_{\left(M_{1}, \rho_{1}\right)}\left(y_{n}-\rho_{1} B_{1} y_{n}\right)-J_{\left(M_{1}, \rho_{1}\right)}\left(\bar{y}-\rho_{1} B_{1} \bar{y}\right)\right\| \\
& \leq\left\|\left(y_{n}-\rho_{1} B_{1} y_{n}\right)-\left(\bar{y}-\rho_{1} B_{1} \bar{y}\right)\right\| \\
& \leq\left\|y_{n}-\bar{y}\right\| \\
& =\left\|J_{\left(M_{2}, \rho_{2}\right)}\left(z_{n}-\rho_{2} B_{2} z_{n}\right)-J_{\left(M_{2}, \rho_{2}\right)}\left(\bar{z}-\rho_{2} B_{2} \bar{z}\right)\right\| \\
& \leq\left\|\left(z_{n}-\rho_{2} B_{2} z_{n}\right)-\left(\bar{z}-\rho_{2} B_{2} \bar{z}\right)\right\| \\
& \leq\left\|z_{n}-\bar{z}\right\| \\
& =\left\|J_{\left(M_{3}, \rho_{3}\right)}\left(x_{n}-\rho_{3} B_{3} x_{n}\right)-J_{\left(M_{3}, \rho_{3}\right)}\left(\bar{x}-\rho_{3} B_{3} \bar{x}\right)\right\| \\
& \leq\left\|\left(x_{n}-\rho_{3} B_{3} x_{n}\right)-\left(\bar{x}-\rho_{3} B_{3} \bar{x}\right)\right\| \\
& \leq\left\|x_{n}-\bar{x}\right\|
\end{aligned}
$$

and setting $\epsilon_{n}=\mu\left(1 / t_{n}\right) \int_{0}^{t_{n}} T(s) x_{n} d s+(1-\mu) v_{n}$. From (3.6), we obtain

$$
\begin{aligned}
\left\|\epsilon_{n}-\bar{x}\right\| & =\left\|\mu\left(\frac{1}{t_{n}} \int_{0}^{t_{n}} T(s) x_{n} d s-\bar{x}\right)+(1-\mu)\left(v_{n}-\bar{x}\right)\right\| \\
& \leq \mu\left\|\frac{1}{t_{n}} \int_{0}^{t_{n}} T(s) x_{n} d s-\bar{x}\right\|+(1-\mu)\left\|v_{n}-\bar{x}\right\| \\
& \leq \mu\left\|x_{n}-\bar{x}\right\|+(1-\mu)\left\|x_{n}-\bar{x}\right\| \\
& =\left\|x_{n}-\bar{x}\right\| .
\end{aligned}
$$

It follows from (3.7) that

$$
\begin{aligned}
\left\|x_{n+1}-\bar{x}\right\| & =\left\|\alpha_{n}\left(\gamma f\left(x_{n}\right)-A \bar{x}\right)+\beta_{n}\left(x_{n}-\bar{x}\right)+\left(\left(1-\beta_{n}\right) I-\alpha_{n} A\right)\left(\epsilon_{n}-\bar{x}\right)\right\| \\
& \leq \alpha_{n}\left\|\gamma f\left(x_{n}\right)-A \bar{x}\right\|+\beta_{n}\left\|x_{n}-\bar{x}\right\|+\left(1-\beta_{n}-\alpha_{n} \bar{\gamma}\right)\left\|\epsilon_{n}-\bar{x}\right\| \\
& \leq \alpha_{n} \gamma\left\|f\left(x_{n}\right)-f(\bar{x})\right\|+\alpha_{n}\|\gamma f(\bar{x})-A \bar{x}\|+\beta_{n}\left\|x_{n}-\bar{x}\right\|+\left(1-\beta_{n}-\alpha_{n} \bar{\gamma}\right)\left\|x_{n}-\bar{x}\right\| \\
& \leq\left(1-\alpha_{n} \bar{\gamma}\right)\left\|x_{n}-\bar{x}\right\|+\alpha_{n} \gamma \alpha\left\|x_{n}-\bar{x}\right\|+\alpha_{n}\|\gamma f(\bar{x})-A \bar{x}\| \\
& =\left(1-\alpha_{n}(\bar{\gamma}-\gamma \alpha)\right)\left\|x_{n}-\bar{x}\right\|+\alpha_{n}\|\gamma f(\bar{x})-A \bar{x}\| \\
& \leq \max \left\{\left\|x_{n}-\bar{x}\right\|, \frac{\|\gamma f(\bar{x})-A \bar{x}\|}{\bar{\gamma}-\gamma \alpha}\right\} .
\end{aligned}
$$


By induction, we have

$$
\left\|x_{n}-\bar{x}\right\| \leq \max \left\{\left\|x_{1}-\bar{x}\right\|, \frac{\|\gamma f(\bar{x})-A \bar{x}\|}{\bar{\gamma}-\gamma \alpha}\right\}, \quad \forall n \geq 1 .
$$

Hence, $\left\{x_{n}\right\}$ is bounded, so are $\left\{z_{n}\right\},\left\{y_{n}\right\}$, and $\left\{v_{n}\right\}$. On the other hand, by nonexpansiveness of $J_{\left(M_{i}, \rho_{i}\right)}$ and $I-\rho_{i} B_{i}$ for all $i=1,2,3$, we have

$$
\begin{aligned}
\left\|v_{n+1}-v_{n}\right\| & =\left\|J_{\left(M_{1}, \rho_{1}\right)}\left(y_{n+1}-\rho_{1} B_{1} y_{n+1}\right)-J_{\left(M_{1}, \rho_{1}\right)}\left(y_{n}-\rho_{1} B_{1} y_{n}\right)\right\| \\
& \leq\left\|\left(y_{n+1}-\rho_{1} B_{1} y_{n+1}\right)-\left(y_{n}-\rho_{1} B_{1} y_{n}\right)\right\| \\
& \leq\left\|y_{n+1}-y_{n}\right\| \\
& =\left\|J_{\left(M_{2}, \rho_{2}\right)}\left(z_{n+1}-\rho_{2} B_{2} z_{n+1}\right)-J_{\left(M_{2}, \rho_{2}\right)}\left(z_{n}-\rho_{2} B_{2} z_{n}\right)\right\| \\
& \leq\left\|z_{n+1}-z_{n}\right\| \\
& =\left\|J_{\left(M_{3}, \rho_{3}\right)}\left(x_{n+1}-\rho_{3} B_{3} x_{n+1}\right)-J_{\left(M_{3}, \rho_{3}\right)}\left(x_{n}-\rho_{3} B_{3} x_{n}\right)\right\| \\
& \leq\left\|x_{n+1}-x_{n}\right\| .
\end{aligned}
$$

Now, we estimate

$$
\begin{aligned}
\left\|\frac{1}{t_{n+1}} \int_{0}^{t_{n+1}} T(s) x_{n+1} d s-\frac{1}{t_{n}} \int_{0}^{t_{n}} T(s) x_{n} d s\right\| \\
=\left\|\frac{1}{t_{n+1}} \int_{0}^{t_{n+1}}\left[T(s) x_{n+1}-T(s) x_{n}\right] d s+\frac{1}{t_{n+1}} \int_{0}^{t_{n+1}} T(s) x_{n} d s-\frac{1}{t_{n}} \int_{0}^{t_{n}} T(s) x_{n} d s\right\| \\
=\| \frac{1}{t_{n+1}} \int_{0}^{t_{n+1}}\left[T(s) x_{n+1}-T(s) x_{n}\right] d s \\
\quad+\frac{1}{t_{n+1}} \int_{0}^{t_{n}} T(s) x_{n} d s+\frac{1}{t_{n+1}} \int_{t_{n}}^{t_{n+1}} T(s) x_{n} d s-\frac{1}{t_{n}} \int_{0}^{t_{n}} T(s) x_{n} d s \| \\
=\left\|\frac{1}{t_{n+1}} \int_{0}^{t_{n+1}}\left[T(s) x_{n+1}-T(s) x_{n}\right] d s+\left(\frac{1}{t_{n+1}}-\frac{1}{t_{n}}\right) \int_{0}^{t_{n}} T(s) x_{n} d s+\frac{1}{t_{n+1}} \int_{t_{n}}^{t_{n+1}} T(s) x_{n} d s\right\|,
\end{aligned}
$$


for $\bar{x} \in \Omega$, it follows that

$$
\begin{aligned}
\left\|\frac{1}{t_{n+1}} \int_{0}^{t_{n+1}} T(s) x_{n+1} d s-\frac{1}{t_{n}} \int_{0}^{t_{n}} T(s) x_{n} d s\right\| \\
=\| \frac{1}{t_{n+1}} \int_{0}^{t_{n+1}}\left[T(s) x_{n+1}-T(s) x_{n}\right] d s \\
\quad+\left(\frac{1}{t_{n+1}}-\frac{1}{t_{n}}\right) \int_{0}^{t_{n}}\left[T(s) x_{n}-\bar{x}\right] d s+\frac{1}{t_{n+1}} \int_{t_{n}}^{t_{n+1}}\left[T(s) x_{n}-\bar{x}\right] d s\|\| \\
\leq \frac{1}{t_{n+1}} \int_{0}^{t_{n+1}}\left\|T(s) x_{n+1}-T(s) x_{n}\right\| d s+\left|\frac{1}{t_{n+1}}-\frac{1}{t_{n}}\right| \int_{0}^{t_{n}}\left\|T(s) x_{n}-\bar{x}\right\| d s \\
\quad+\frac{1}{t_{n+1}} \int_{t_{n}}^{t_{n+1}}\left\|T(s) x_{n}-\bar{x}\right\| d s \\
\leq\left\|x_{n+1}-x_{n}\right\|+\left[\left|\frac{1}{t_{n+1}}-\frac{1}{t_{n}}\right| t_{n}+\frac{1}{t_{n+1}}\left|t_{n+1}-t_{n}\right|\right]\left\|x_{n}-\bar{x}\right\| \\
\leq\left\|x_{n+1}-x_{n}\right\|+\left(\frac{2\left|t_{n+1}-t_{n}\right|}{t_{n+1}}\right)\left\|x_{n}-\bar{x}\right\| .
\end{aligned}
$$

It follows from (3.10) and (3.12) that

$$
\begin{aligned}
\left\|\epsilon_{n+1}-\epsilon_{n}\right\| & =\left\|\left(\mu \frac{1}{t_{n+1}} \int_{0}^{t_{n+1}} T(s) x_{n+1} d s+(1-\mu) v_{n+1}\right)-\left(\mu \frac{1}{t_{n}} \int_{0}^{t_{n}} T(s) x_{n} d s+(1-\mu) v_{n}\right)\right\| \\
& \leq \mu\left\|\frac{1}{t_{n+1}} \int_{0}^{t_{n+1}} T(s) x_{n+1} d s-\frac{1}{t_{n}} \int_{0}^{t_{n}} T(s) x_{n} d s\right\|+(1-\mu)\left\|v_{n+1}-v_{n}\right\| \\
& \leq\left\|x_{n+1}-x_{n}\right\|+\left(\frac{2\left|t_{n+1}-t_{n}\right|}{t_{n+1}}\right)\left\|x_{n}-\bar{x}\right\|+(1-\mu)\left\|x_{n+1}-x_{n}\right\| \\
& \leq\left\|x_{n+1}-x_{n}\right\|+\left(\frac{2\left|t_{n+1}-t_{n}\right|}{t_{n+1}}\right) M_{1}
\end{aligned}
$$

where $M_{1}>0$ is an appropriate constant such that $M_{1}=\sup _{n \geq 1}\left\{\left\|x_{n}-\bar{x}\right\|\right\}$.

Setting $l_{n}=\left(x_{n+1}-\beta_{n} x_{n}\right) /\left(1-\beta_{n}\right)$, for all $n \in \mathbb{N}$. Then $x_{n+1}=\beta_{n} x_{n}+\left(1-\beta_{n}\right) l_{n}$, for all $n \in \mathbb{N}$, we have

$$
\begin{aligned}
l_{n+1}-l_{n} & =\frac{x_{n+2}-\beta_{n+1} x_{n+1}}{1-\beta_{n+1}}-\frac{x_{n+1}-\beta_{n} x_{n}}{1-\beta_{n}} \\
& =\frac{\alpha_{n+1} \gamma f\left(x_{n+1}\right)+\left(\left(1-\beta_{n+1}\right) I-\alpha_{n+1} A\right) \epsilon_{n+1}}{1-\beta_{n+1}}-\frac{\alpha_{n} \gamma f\left(x_{n}\right)+\left(\left(1-\beta_{n}\right) I-\alpha_{n} A\right) \epsilon_{n}}{1-\beta_{n}} \\
& =\frac{\alpha_{n+1}}{1-\beta_{n+1}}\left(\gamma f\left(x_{n+1}\right)-A \epsilon_{n+1}\right)+\frac{\alpha_{n}}{1-\beta_{n}}\left(A \epsilon_{n}-\gamma f\left(x_{n}\right)\right)+\epsilon_{n+1}-\epsilon_{n}
\end{aligned}
$$


Journal of Applied Mathematics

and, hence,

$$
\left\|l_{n+1}-l_{n}\right\| \leq \frac{\alpha_{n+1}}{1-\beta_{n+1}}\left\|\gamma f\left(x_{n+1}\right)-A \epsilon_{n+1}\right\|+\frac{\alpha_{n}}{1-\beta_{n}}\left\|A \epsilon_{n}-\gamma f\left(x_{n}\right)\right\|+\left\|\epsilon_{n+1}-\epsilon_{n}\right\|,
$$

which, combined with (3.13) yields that

$$
\begin{aligned}
\left\|l_{n+1}-l_{n}\right\| \leq & \frac{\alpha_{n+1}}{1-\beta_{n+1}}\left\|\gamma f\left(x_{n+1}\right)-A \epsilon_{n+1}\right\|+\frac{\alpha_{n}}{1-\beta_{n}}\left\|A \epsilon_{n}-\gamma f\left(x_{n}\right)\right\| \\
& +\left\|x_{n+1}-x_{n}\right\|+\left(\frac{2\left|t_{n+1}-t_{n}\right|}{t_{n+1}}\right) M_{1} .
\end{aligned}
$$

It follows that

$$
\begin{aligned}
\left\|l_{n+1}-l_{n}\right\|-\left\|x_{n+1}-x_{n}\right\| \leq & \frac{\alpha_{n+1}}{1-\beta_{n+1}}\left\|\gamma f\left(x_{n+1}\right)-A \epsilon_{n+1}\right\| \\
& +\frac{\alpha_{n}}{1-\beta_{n}}\left\|A \epsilon_{n}-\gamma f\left(x_{n}\right)\right\|+\left(\frac{2\left|t_{n+1}-t_{n}\right|}{t_{n+1}}\right) M_{1} .
\end{aligned}
$$

By conditions (C1)-(C3), we have

$$
\limsup _{n \rightarrow \infty}\left(\left\|l_{n+1}-l_{n}\right\|-\left\|x_{n+1}-x_{n}\right\|\right) \leq 0
$$

Then, from Lemma 2.12, we obtain

$$
\lim _{n \rightarrow \infty}\left\|l_{n}-x_{n}\right\|=0
$$

observing that

$$
x_{n+1}-x_{n}=\left(1-\beta_{n}\right)\left(l_{n}-x_{n}\right),
$$

and, hence,

$$
\lim _{n \rightarrow \infty}\left\|x_{n+1}-x_{n}\right\|=0
$$

Since $x_{n+1}=\alpha_{n} \gamma f\left(x_{n}\right)+\beta_{n} x_{n}+\left(\left(1-\beta_{n}\right) I-\alpha_{n} A\right) \epsilon_{n}$, then we have

$$
x_{n+1}-x_{n}=\alpha_{n}\left(\gamma f\left(x_{n}\right)-A x_{n}\right)+\left(\left(1-\beta_{n}\right) I-\alpha_{n} A\right)\left(\epsilon_{n}-x_{n}\right) .
$$

It follows that

$$
\left(1-\beta_{n}-\alpha_{n} \bar{\gamma}\right)\left\|\epsilon_{n}-x_{n}\right\| \leq\left\|x_{n}-x_{n+1}\right\|+\alpha_{n}\left\|\gamma f\left(x_{n}\right)-A x_{n}\right\| .
$$


From (3.21) and by the conditions (C1), (C2), we obtain that

$$
\lim _{n \rightarrow \infty}\left\|\epsilon_{n}-x_{n}\right\|=0
$$

Define the mapping $G_{n}$ by

$$
G_{n} x=\mu \frac{1}{t_{n}} \int_{0}^{t_{n}} T(s) x d s+(1-\mu) Q x, \quad \forall x \in X,
$$

where $Q$ is defined as in Lemma 2.17. By Lemma 2.11, we see that $G_{n}$ is nonexpansive such that

$$
F\left(G_{n}\right)=F(\mathcal{S}) \cap F(Q)
$$

From (3.24), it follows that

$$
\lim _{n \rightarrow \infty}\left\|G_{n} x_{n}-x_{n}\right\|=0 .
$$

Since $\left\{T(t): t \in \mathbb{R}^{+}\right\}$is a u.a.r. nonexpansive semigroup by Remark 2.6, and at least there exists a $T(t)$ which is demicompact, then by Lemma 2.7, we can define the mapping $T: X \rightarrow$ $X$ such that $T y=\lim _{n \rightarrow \infty}\left(1 / t_{n}\right) \int_{0}^{t_{n}} T(s) y d s$ for all $y \in X$. Furthermore, let $G: X \rightarrow X$ be the mapping define by $G y=\lim _{n \rightarrow \infty} G_{n} y$, for all $y \in X$. It follows from the nonexpansivity of $G$ and

$$
G y:=\mu T y+(1-\mu) Q y, \quad \forall y \in X,
$$

such that

$$
F(G)=F(T) \cap F(Q)=F(\mathcal{S}) \cap F(Q)=F\left(G_{n}\right) .
$$

On the other hand, we observe that for any bounded subset $C$ of $X$ containing $\left\{x_{n}\right\}$,

$$
\begin{aligned}
\left\|x_{n}-G x_{n}\right\| & \leq\left\|x_{n}-G_{n} x_{n}\right\|+\left\|G_{n} x_{n}-G x_{n}\right\| \\
& \leq\left\|x_{n}-G_{n} x_{n}\right\|+\sup _{\omega \in C}\left\|G_{n} \omega-G \omega\right\| .
\end{aligned}
$$

By Lemma 2.7 and (3.27), we obtain that

$$
\lim _{n \rightarrow \infty}\left\|x_{n}-G x_{n}\right\|=0
$$

Since $X$ is a uniformly convex, hence it is reflexive and $\left\{x_{n}\right\}$ is bounded, then there exists a subsequence $\left\{x_{n_{j}}\right\}$ of $\left\{x_{n}\right\}$ which converges weakly to some $z \in X$ as $j \rightarrow \infty$. Again, since 
Banach space $X$ has a weakly sequentially continuous duality mapping satisfying Opial's condition, then by (3.32), we have by Lemma 2.14, that $z \in F(G)=\Omega$.

Next, we show that $\lim \sup _{n \rightarrow \infty}\left\langle\gamma f\left(x^{*}\right)-A x^{*}, J\left(x_{n}-x^{*}\right)\right\rangle \leq 0$, where $x^{*}=\lim _{t \rightarrow 0} x_{t}$ with $x_{t}$ be the fixed point of the contraction $x \mapsto t \gamma f(x)+(I-t A) G x$. Since $G$ is a nonexpansive mapping, it follows from Lemma 2.10 that $x^{*} \in F(G)=\Omega$, which solves the variational inequality

$$
\left\langle(\gamma f-A) x^{*}, J\left(z-x^{*}\right)\right\rangle \leq 0, \quad \forall z \in F(G)
$$

and $\left(x^{*}, y^{*}, z^{*}\right)$ is a solution of general system of variational inequality problem (1.38) such that $y^{*}=J_{\left(M_{2}, \rho_{2}\right)}\left(z^{*}-\rho_{2} B_{2} z^{*}\right)$ and $z^{*}=J_{\left(M_{3}, \rho_{3}\right)}\left(x^{*}-\rho_{3} B_{3} x^{*}\right)$.

Let $\left\{x_{n_{j}}\right\}$ be a subsequence of $\left\{x_{n}\right\}$ such that

$$
\limsup _{n \rightarrow \infty}\left\langle\gamma f\left(x^{*}\right)-A x^{*}, J\left(x_{n}-x^{*}\right)\right\rangle=\lim _{j \rightarrow \infty}\left\langle\gamma f\left(x^{*}\right)-A x^{*}, J\left(x_{n_{j}}-x^{*}\right)\right\rangle .
$$

Since the duality mapping $J$ is single-valued and weakly sequentially continuous from $X$ to $X^{*}$, we obtain that

$$
\begin{aligned}
\limsup _{n \rightarrow \infty}\left\langle\gamma f\left(x^{*}\right)-A x^{*}, J\left(x_{n}-x^{*}\right)\right\rangle & =\lim _{j \rightarrow \infty}\left\langle\gamma f\left(x^{*}\right)-A x^{*}, J\left(x_{n_{j}}-x^{*}\right)\right\rangle \\
& =\left\langle\gamma f\left(x^{*}\right)-A x^{*}, J\left(z-x^{*}\right)\right\rangle \leq 0,
\end{aligned}
$$

as required.

Finally, we show that $\lim _{n \rightarrow \infty}\left\|x_{n}-x^{*}\right\|=0$. Now, from Lemma 2.3, we have

$$
\begin{aligned}
\left\|x_{n+1}-x^{*}\right\|^{2}= & \left\|\alpha_{n}\left(\gamma f\left(x_{n}\right)-A x^{*}\right)+\beta_{n}\left(x_{n}-x^{*}\right)+\left(\left(1-\beta_{n}\right) I-\alpha_{n} A\right)\left(\epsilon_{n}-x^{*}\right)\right\|^{2} \\
\leq & \left\|\left(\left(1-\beta_{n}\right) I-\alpha_{n} A\right)\left(\epsilon_{n}-x^{*}\right)+\beta_{n}\left(x_{n}-x^{*}\right)\right\|^{2} \\
& +2 \alpha_{n}\left\langle\gamma f\left(x_{n}\right)-A x^{*}, J\left(x_{n+1}-x^{*}\right)\right\rangle \\
\leq & \left(\left(1-\beta_{n}-\alpha_{n} \bar{\gamma}\right)\left\|\epsilon_{n}-x^{*}\right\|+\beta_{n}\left\|x_{n}-x^{*}\right\|\right)^{2}+2 \alpha_{n}\left\langle\gamma f\left(x_{n}\right)-A x^{*}, J\left(x_{n+1}-x^{*}\right)\right\rangle \\
\leq & \left(1-\alpha_{n} \bar{\gamma}\right)^{2}\left\|x_{n}-x^{*}\right\|^{2}+2 \alpha_{n} \gamma\left\langle f\left(x_{n}\right)-f\left(x^{*}\right), J\left(x_{n+1}-x^{*}\right)\right\rangle \\
& +2 \alpha_{n}\left\langle\gamma f\left(x^{*}\right)-A x^{*}, J\left(x_{n+1}-x^{*}\right)\right\rangle \\
\leq & \left(1-\alpha_{n} \bar{\gamma}\right)^{2}\left\|x_{n}-x^{*}\right\|^{2}+2 \alpha_{n} \gamma \alpha\left\|x_{n}-x^{*}\right\|\left\|x_{n+1}-x^{*}\right\| \\
& +2 \alpha_{n}\left\langle\gamma f\left(x^{*}\right)-A x^{*}, J\left(x_{n+1}-x^{*}\right)\right\rangle \\
\leq & \left(1-\alpha_{n} \bar{\gamma}\right)^{2}\left\|x_{n}-x^{*}\right\|^{2}+\alpha_{n} \gamma \alpha\left(\left\|x_{n}-x^{*}\right\|^{2}+\left\|x_{n+1}-x^{*}\right\|^{2}\right) \\
& +2 \alpha_{n}\left\langle\gamma f\left(x^{*}\right)-A x^{*}, J\left(x_{n+1}-x^{*}\right)\right\rangle,
\end{aligned}
$$


which implies that

$$
\begin{aligned}
\left\|x_{n+1}-x^{*}\right\|^{2} \leq & \frac{\left(1-\alpha_{n} \bar{\gamma}\right)^{2}+\alpha_{n} \gamma \alpha}{1-\alpha_{n} \gamma \alpha}\left\|x_{n}-x^{*}\right\|^{2}+\frac{2 \alpha_{n}}{1-\alpha_{n} \gamma \alpha}\left\langle\gamma f\left(x^{*}\right)-A x^{*}, J\left(x_{n+1}-x^{*}\right)\right\rangle \\
= & \frac{1-2 \alpha_{n} \bar{\gamma}+\alpha_{n} \gamma \alpha}{1-\alpha_{n} \gamma \alpha}\left\|x_{n}-x^{*}\right\|^{2}+\frac{\alpha_{n}^{2} \bar{\gamma}^{2}}{1-\alpha_{n} \gamma \alpha}\left\|x_{n}-x^{*}\right\|^{2} \\
& +\frac{2 \alpha_{n}}{1-\alpha_{n} \gamma \alpha}\left\langle\gamma f\left(x^{*}\right)-A x^{*}, J\left(x_{n+1}-x^{*}\right)\right\rangle \\
\leq & {\left[1-\frac{2 \alpha_{n}(\bar{\gamma}-\gamma \alpha)}{1-\alpha_{n} \gamma \alpha}\right]\left\|x_{n}-x^{*}\right\|^{2} } \\
& +\frac{2 \alpha_{n}(\bar{\gamma}-\gamma \alpha)}{1-\alpha_{n} \gamma \alpha}\left[\frac{1}{\bar{\gamma}-\gamma \alpha}\left\langle\gamma f\left(x^{*}\right)-A x^{*}, J\left(x_{n+1}-x^{*}\right)\right\rangle+\frac{\alpha_{n} \bar{\gamma}^{2}}{2(\bar{\gamma}-\gamma \alpha)} M_{2}\right],
\end{aligned}
$$

where $M_{2}>0$ is an appropriate constant such that $M_{2}=\sup _{n \geq 1}\left\{\left\|x_{n}-x^{*}\right\|\right\}$. Put $\tau_{n}=2 \alpha_{n}(\bar{\gamma}-$ $\gamma \alpha) /\left(1-\alpha_{n} \gamma \alpha\right)$ and $\delta_{n}=(1 /(\bar{\gamma}-\gamma \alpha))\left\langle\gamma f\left(x^{*}\right)-A x^{*}, J\left(x_{n+1}-x^{*}\right)\right\rangle+\left(\alpha_{n} \bar{\gamma}^{2} / 2(\bar{\gamma}-\gamma \alpha)\right) M_{2}$. Then (3.32) reduces to formula

$$
\left\|x_{n+1}-x^{*}\right\|^{2} \leq\left(1-\tau_{n}\right)\left\|x_{n}-x^{*}\right\|^{2}+\tau_{n} \delta_{n}
$$

By the condition (C1) and (3.31), it easy to see that

$$
\lim _{n \rightarrow \infty} \tau_{n}=0, \quad \sum_{n=1}^{\infty} \tau_{n}=\infty, \quad \limsup _{n \rightarrow \infty} \delta_{n} \leq 0
$$

Applying Lemma 2.15 to (3.37), we obtain $x_{n} \rightarrow x^{*}$ as $n \rightarrow \infty$, that is $\lim _{n \rightarrow \infty}\left\|x_{n}-x^{*}\right\|=0$. This completes the proof.

Remark 3.2. Theorem 3.1 mainly improves Theorem 2.1 of Qin et al. [8], in the following respects:

(1) from a system variational inclusion to a general system of variational inclusions,

(2) from the class of inverse-strongly accretive mappings to the class of Lipchitzian and relaxed cocoercive mappings.

Taking $A \equiv I$ and $\gamma=1$ in Theorem 3.1, we can obtain the following result.

Corollary 3.3. Let $X$ be a uniformly convex and 2-uniformly smooth Banach space which admits a weakly continuous duality mapping and has the smoothness constant $K$. Let $M_{i}: X \rightarrow 2^{X}$ be a maximal monotone mapping and $B_{i}: X \rightarrow X$ be a $L_{i}$-Lipschitzian and relaxed $\left(c_{i}, d_{i}\right)$-cocoercive mapping with $\rho_{i} \in\left(0,\left(d_{i}-c_{i} L_{i}^{2}\right) / K^{2} L_{i}^{2}\right]$ and $\theta_{\rho}=\max \left\{\theta_{\rho_{i}}\right\}$ for all $i=1,2,3$. Let $\mathcal{S}=\left\{T(t): t \in \mathbb{R}^{+}\right\}$ 
be a nonexpansive semigroup from $X$ into itself and at least there exists a $T(t)$ which is demicompact. Assume that $\Omega:=F(\mathcal{S}) \cap F(Q) \neq \emptyset$, where $Q$ is defined as in Lemma 2.17. Let $f: X \rightarrow X$ be a contraction mapping with a coefficient $\alpha \in(0,1)$. Let $\left\{x_{n}\right\}$ be a sequence defined by

$$
\begin{gathered}
x_{1} \in X \text { chosen arbitrarily, } \\
z_{n}=J_{\left(M_{3}, \rho_{3}\right)}\left(x_{n}-\rho_{3} B_{3} x_{n}\right), \\
y_{n}=J_{\left(M_{2}, \rho_{2}\right)}\left(z_{n}-\rho_{2} B_{2} z_{n}\right), \\
v_{n}=J_{\left(M_{1}, \rho_{1}\right)}\left(y_{n}-\rho_{1} B_{1} y_{n}\right), \\
x_{n+1}=\alpha_{n} f\left(x_{n}\right)+\beta_{n} x_{n}+\left(1-\beta_{n}-\alpha_{n}\right)\left[\mu \frac{1}{t_{n}} \int_{0}^{t_{n}} T(s) x_{n} d s+(1-\mu) v_{n}\right], \quad \forall n \geq 1,
\end{gathered}
$$

where $\mu \in(0,1),\left\{\alpha_{n}\right\}_{n=1}^{\infty},\left\{\beta_{n}\right\}_{n=1}^{\infty}$ are the sequences in $(0,1)$ which satisfies $\alpha_{n}+\beta_{n} \leq 1$ and $\left\{t_{n}\right\}_{n=1}^{\infty}$ is a positive real divergent sequence satisfy the following restrictions:

(C1) $\lim _{n \rightarrow \infty} \alpha_{n}=0$ and $\sum_{n=1}^{\infty} \alpha_{n}=\infty$,

(C2) $0<\lim \inf _{n \rightarrow \infty} \beta_{n} \leq \lim \sup _{n \rightarrow \infty} \beta_{n}<1$,

(C3) $\lim _{n \rightarrow \infty}\left(\left|t_{n+1}-t_{n}\right| / t_{n+1}\right)=0$.

Then the sequence $\left\{x_{n}\right\}$ defined by (3.39) converges strongly to $x^{*}$, which $x^{*}$ solves the variational inequality

$$
\left\langle(f-I) x^{*}, J\left(z-x^{*}\right)\right\rangle \leq 0, \quad \forall z \in \Omega,
$$

and $\left(x^{*}, y^{*}, z^{*}\right)$ is a solution of general system of variational inequality problem (1.38), where $y^{*}=$ $J_{\left(M_{2}, \rho_{2}\right)}\left(z^{*}-\rho_{2} B_{2} z^{*}\right)$ and $z^{*}=J_{\left(M_{3}, \rho_{3}\right)}\left(x^{*}-\rho_{3} B_{3} x^{*}\right)$.

Taking $f(x)=u$ in Corollary 3.3, we can obtain the following result.

Corollary 3.4. Let $X$ be a uniformly convex and 2-uniformly smooth Banach space which admits a weakly continuous duality mapping and has the smoothness constant $K$. Let $M_{i}: X \rightarrow 2^{X}$ be a maximal monotone mapping and $B_{i}: X \rightarrow X$ be a $L_{i}$-Lipschitzian and relaxed $\left(c_{i}, d_{i}\right)$-cocoercive mapping with $\rho_{i} \in\left(0,\left(d_{i}-c_{i} L_{i}^{2}\right) / K^{2} L_{i}^{2}\right]$ and $\theta_{\rho}=\max \left\{\theta_{\rho_{i}}\right\}$ for all $i=1,2,3$. Let $\mathcal{S}=\{T(t)$ : $\left.t \in \mathbb{R}^{+}\right\}$be a nonexpansive semigroup from $X$ into itself and at least there exists a $T(t)$ which is demicompact. Assume that $\Omega:=F(\mathcal{S}) \cap F(Q) \neq \emptyset$, where $Q$ is defined as in Lemma 2.17. Let $\left\{x_{n}\right\}$ be a sequence defined by

$$
\begin{gathered}
x_{1} \in X \text { chosen arbitrarily, } \\
z_{n}=J_{\left(M, \rho_{3}\right)}\left(x_{n}-\rho_{3} B_{3} x_{n}\right), \\
y_{n}=J_{\left(M, \rho_{2}\right)}\left(z_{n}-\rho_{2} B_{2} z_{n}\right), \\
v_{n}=J_{\left(M, \rho_{1}\right)}\left(y_{n}-\rho_{1} B_{1} y_{n}\right), \\
x_{n+1}=\alpha_{n} u+\beta_{n} x_{n}+\left(1-\beta_{n}-\alpha_{n}\right)\left[\mu \frac{1}{t_{n}} \int_{0}^{t_{n}} T(s) x_{n} d s+(1-\mu) v_{n}\right], \quad \forall n \geq 1,
\end{gathered}
$$


where $\mu \in(0,1),\left\{\alpha_{n}\right\}_{n=1}^{\infty},\left\{\beta_{n}\right\}_{n=1}^{\infty}$ are the sequences in $(0,1)$ which satisfies $\alpha_{n}+\beta_{n} \leq 1$ and $\left\{t_{n}\right\}_{n=1}^{\infty}$ is a positive real divergent sequence satisfy the following restrictions:

(C1) $\lim _{n \rightarrow \infty} \alpha_{n}=0$ and $\sum_{n=1}^{\infty} \alpha_{n}=\infty$,

(C2) $0<\lim \inf _{n \rightarrow \infty} \beta_{n} \leq \lim \sup _{n \rightarrow \infty} \beta_{n}<1$,

(C3) $\lim _{n \rightarrow \infty}\left(\left|t_{n+1}-t_{n}\right| / t_{n+1}\right)=0$.

Then the sequence $\left\{x_{n}\right\}$ defined by (3.41) converges strongly to $x^{*}$, which $x^{*}$ solves the variational inequality

$$
\left\langle u-x^{*}, J\left(z-x^{*}\right)\right\rangle \leq 0, \quad \forall z \in \Omega,
$$

and $\left(x^{*}, y^{*}, z^{*}\right)$ is a solution of general system of variational inequality problem (1.38), where $y^{*}=$ $J_{\left(M_{2}, \rho_{2}\right)}\left(z^{*}-\rho_{2} B_{2} z^{*}\right)$ and $z^{*}=J_{\left(M_{3}, \rho_{3}\right)}\left(x^{*}-\rho_{3} B_{3} x^{*}\right)$.

\section{Some Applications}

As some applications of Theorem 3.1, we obtain the following results.

Lemma 4.1. For all $\left(x^{*}, y^{*}, z^{*}\right) \in X \times X \times X$, where $y^{*}=J_{\left(M, \rho_{2}\right)}\left(z^{*}-\rho_{2} B z^{*}\right)$ and $z^{*}=J_{\left(M, \rho_{3}\right)}\left(x^{*}-\right.$ $\left.\rho_{3} B x^{*}\right),\left(x^{*}, y^{*}, z^{*}\right)$ is a solution of the problem (1.39) if and only if $x^{*}$ is a fixed point of the mapping $Q^{\prime}$ defined by

$$
\begin{aligned}
Q^{\prime} x:=J_{\left(M, \rho_{1}\right)}\left(J_{\left(M, \rho_{2}\right)}\right. & \left(J_{\left(M, \rho_{3}\right)}\left(x-\rho_{3} B x\right)-\rho_{2} B J_{\left(M, \rho_{3}\right)}\left(x-\rho_{3} B x\right)\right. \\
& \left.\left.-\rho_{1} B J_{\left(M, \rho_{2}\right)} J_{\left(M, \rho_{3}\right)}\left(x-\rho_{3} B x\right)-\rho_{2} B J_{\left(M, \rho_{3}\right)}\left(x-\rho_{3} B x\right)\right)\right), \quad \forall x \in X .
\end{aligned}
$$

Corollary 4.2. Let $X$ be a uniformly convex and 2-uniformly smooth Banach space which admits a weakly continuous duality mapping and has the smoothness constant $K$. Let $M: X \rightarrow 2^{X}$ be a maximal monotone mapping and $B: X \rightarrow X$ be a L-Lipschitzian and relaxed $(c, d)$-cocoercive mapping with $\rho_{i} \in\left(0,\left(d-c L^{2}\right) / K^{2} L^{2}\right]$ and $\theta_{\rho}=\max \left\{\theta_{\rho_{i}}\right\}$ for all $i=1,2,3$. Let $\mathcal{S}=\left\{T(t): t \in \mathbb{R}^{+}\right\}$ be a nonexpansive semigroup from $X$ into itself and at least there exists a $T(t)$ which is demicompact. Assume that $\Omega:=F(\mathcal{S}) \cap F\left(Q^{\prime}\right) \neq \emptyset$, where $Q^{\prime}$ is defined as in Lemma 4.1. Let $f: X \rightarrow X$ be a contraction mapping with a coefficient $\alpha \in(0,1)$ and $A$ be a strongly positive linear bounded self adjoint operator with a coefficient $\bar{\gamma} \in(0,1)$ such that $\|A\| \leq 1$ and $0<\gamma<\bar{\gamma} / \alpha$. Let $\left\{x_{n}\right\}$ be a sequence defined by

$$
\begin{aligned}
& x_{1} \in X \text { chosen arbitrarily, } \\
& z_{n}=J_{\left(M, \rho_{3}\right)}\left(x_{n}-\rho_{3} B x_{n}\right), \\
& y_{n}=J_{\left(M, \rho_{2}\right)}\left(z_{n}-\rho_{2} B z_{n}\right), \\
& v_{n}=J_{\left(M, \rho_{1}\right)}\left(y_{n}-\rho_{1} B y_{n}\right), \\
& x_{n+1}=\alpha_{n} \gamma f\left(x_{n}\right)+\beta_{n} x_{n}+\left(\left(1-\beta_{n}\right) I-\alpha_{n} A\right)\left[\mu \frac{1}{t_{n}} \int_{0}^{t_{n}} T(s) x_{n} d s+(1-\mu) v_{n}\right], \quad \forall n \geq 1,
\end{aligned}
$$


where $\mu \in(0,1),\left\{\alpha_{n}\right\}_{n=1}^{\infty},\left\{\beta_{n}\right\}_{n=1}^{\infty}$ are the sequences in $(0,1)$ which satisfies $\alpha_{n}+\beta_{n} \leq 1$ and $\left\{t_{n}\right\}_{n=1}^{\infty}$ is a positive real divergent sequence satisfy the following restrictions:

(C1) $\lim _{n \rightarrow \infty} \alpha_{n}=0$ and $\sum_{n=1}^{\infty} \alpha_{n}=\infty$,

(C2) $0<\lim \inf _{n \rightarrow \infty} \beta_{n} \leq \lim \sup _{n \rightarrow \infty} \beta_{n}<1$,

(C3) $\lim _{n \rightarrow \infty}\left(\left|t_{n+1}-t_{n}\right| / t_{n+1}\right)=0$.

Then the sequence $\left\{x_{n}\right\}$ defined by (4.2) converges strongly to $x^{*}$, which $x^{*}$ solves the variational inequality

$$
\left\langle(\gamma f-A) x^{*}, J\left(z-x^{*}\right)\right\rangle \leq 0, \quad \forall z \in \Omega,
$$

and $\left(x^{*}, y^{*}, z^{*}\right)$ is a solution of system of variational inequality problem (1.39), where $y^{*}=J_{\left(M, \rho_{2}\right)}\left(z^{*}-\right.$ $\left.\rho_{2} B z^{*}\right)$ and $z^{*}=J_{\left(M, \rho_{3}\right)}\left(x^{*}-\rho_{3} B x^{*}\right)$.

Lemma 4.3 (see [8]). For all $\left(x^{*}, y^{*}\right) \in X \times X$, where $y^{*}=J_{\left(M_{2}, \rho_{2}\right)}\left(x^{*}-\rho_{2} B_{2} x^{*}\right),\left(x^{*}, y^{*}\right)$ is a solution of the problem (1.15) if and only if $x^{*}$ is a fixed point of the mapping $Q^{\prime}$ defined by

$$
Q^{\prime} x:=J_{\left(M_{1}, \rho_{1}\right)}\left[J_{\left(M_{2}, \rho_{2}\right)}\left(x-\rho_{2} B_{2} x\right)-\rho_{1} B_{1} J_{\left(M_{2}, \rho_{2}\right)}\left(x-\rho_{2} B_{2} x\right)\right] .
$$

Corollary 4.4. Let $X$ be a uniformly convex and 2-uniformly smooth Banach space which admits a weakly continuous duality mapping and has the smoothness constant $K$. Let $M_{i}: X \rightarrow 2^{X}$ be a maximal monotone mapping and $B_{i}: X \rightarrow X$ be a $L_{i}$-Lipschitzian and relaxed $\left(c_{i}, d_{i}\right)$-cocoercive mapping with $\rho_{i} \in\left(0,\left(d_{i}-c_{i} L_{i}^{2}\right) / K^{2} L_{i}^{2}\right]$ and $\theta_{\rho}=\max \left\{\theta_{\rho_{i}}\right\}$ for all $i=1,2$. Let $\mathcal{S}=\left\{T(t): t \in \mathbb{R}^{+}\right\}$ be a nonexpansive semigroup from $X$ into itself and at least there exists a $T(t)$ which is demicompact. Assume that $\Omega:=F(\mathcal{S}) \cap F\left(Q^{\prime}\right) \neq \emptyset$, where $Q^{\prime}$ is defined as in Lemma 4.3. Let $f: X \rightarrow X$ be a contraction mapping with a coefficient $\alpha \in(0,1)$ and $A$ be a strongly positive linear bounded self adjoint operator with a coefficient $\bar{\gamma} \in(0,1)$ such that $\|A\| \leq 1$ and $0<\gamma<\bar{\gamma} / \alpha$. Let $\left\{x_{n}\right\}$ be a sequence defined by

$$
\begin{gathered}
x_{1} \in X \text { chosen arbitrarily, } \\
y_{n}=J_{\left(M, \rho_{2}\right)}\left(x_{n}-\rho_{2} B_{2} x_{n}\right), \\
v_{n}=J_{\left(M, \rho_{1}\right)}\left(y_{n}-\rho_{1} B_{1} y_{n}\right), \\
x_{n+1}=\alpha_{n} \gamma f\left(x_{n}\right)+\beta_{n} x_{n}+\left(\left(1-\beta_{n}\right) I-\alpha_{n} A\right)\left[\mu \frac{1}{t_{n}} \int_{0}^{t_{n}} T(s) x_{n} d s+(1-\mu) v_{n}\right], \quad \forall n \geq 1,
\end{gathered}
$$

where $\mu \in(0,1),\left\{\alpha_{n}\right\}_{n=1}^{\infty},\left\{\beta_{n}\right\}_{n=1}^{\infty}$ are the sequences in $(0,1)$ which satisfies $\alpha_{n}+\beta_{n} \leq 1$ and $\left\{t_{n}\right\}_{n=1}^{\infty}$ is a positive real divergent sequence satisfy the following restrictions:

(C1) $\lim _{n \rightarrow \infty} \alpha_{n}=0$ and $\sum_{n=1}^{\infty} \alpha_{n}=\infty$,

(C2) $0<\lim \inf _{n \rightarrow \infty} \beta_{n} \leq \lim \sup _{n \rightarrow \infty} \beta_{n}<1$,

(C3) $\lim _{n \rightarrow \infty}\left(\left|t_{n+1}-t_{n}\right| / t_{n+1}\right)=0$. 
Then the sequence $\left\{x_{n}\right\}$ defined by (4.5) converges strongly to $x^{*}$, which $x^{*}$ solves the variational inequality

$$
\left\langle(\gamma f-A) x^{*}, J\left(z-x^{*}\right)\right\rangle \leq 0, \quad \forall z \in \Omega,
$$

and $\left(x^{*}, y^{*}\right)$ is a solution of system of variational inequality problem $(1.15)$, where $y^{*}=J_{\left(M_{2}, \rho_{2}\right)}\left(x^{*}-\right.$ $\left.\rho_{2} B_{2} x^{*}\right)$.

If we set $B_{1}=B_{2}=B$ and $M_{1}=M_{2}=M$, we obtain the following result.

Lemma 4.5 (see [8]). For all $\left(x^{*}, y^{*}\right) \in X \times X$, where $y^{*}=J_{\left(M, \rho_{2}\right)}\left(x^{*}-\rho_{2} B x^{*}\right),\left(x^{*}, y^{*}\right)$ is a solution of the problem (1.16) if and only if $x^{*}$ is a fixed point of the mapping $Q^{\prime \prime}$ defined by

$$
Q^{\prime \prime} x:=J_{\left(M, \rho_{1}\right)}\left[J_{\left(M, \rho_{2}\right)}\left(x-\rho_{2} B x\right)-\rho_{1} B J_{\left(M, \rho_{2}\right)}\left(x-\rho_{2} B x\right)\right] .
$$

Corollary 4.6. Let $X$ be a uniformly convex and 2-uniformly smooth Banach space which admits a weakly continuous duality mapping and has the smoothness constant $K$. Let $M: X \rightarrow 2^{X}$ be a maximal monotone mapping and $B: X \rightarrow X$ be a L-Lipschitzian and relaxed $(c, d)$-cocoercive mapping with $\rho_{i} \in\left(0,\left(d-c L^{2}\right) / K^{2} L^{2}\right]$ and $\theta_{\rho}=\max \left\{\theta_{\rho_{i}}\right\}$ for all $i=1,2$. Let $\mathcal{S}=\left\{T(t): t \in \mathbb{R}^{+}\right\}$ be a nonexpansive semigroup from $X$ into itself and at least there exists a $T(t)$ which is demicompact. Assume that $\Omega:=F(S) \cap F\left(Q^{\prime}\right) \neq \emptyset$, where $Q^{\prime \prime}$ is defined as in Lemma 4.5. Let $f: X \rightarrow X$ be a contraction mapping with a coefficient $\alpha \in(0,1)$ and $A$ be a strongly positive linear bounded self adjoint operator with a coefficient $\bar{\gamma} \in(0,1)$ such that $\|A\| \leq 1$ and $0<\gamma<\bar{\gamma} / \alpha$. Let $\left\{x_{n}\right\}$ be a sequence defined by

$$
\begin{gathered}
x_{1} \in X \text { chosen arbitrarily, } \\
y_{n}=J_{\left(M, \rho_{2}\right)}\left(x_{n}-\rho_{2} B x_{n}\right), \\
v_{n}=J_{\left(M, \rho_{1}\right)}\left(y_{n}-\rho_{1} B y_{n}\right), \\
x_{n+1}=\alpha_{n} \gamma f\left(x_{n}\right)+\beta_{n} x_{n}+\left(\left(1-\beta_{n}\right) I-\alpha_{n} A\right)\left[\mu \frac{1}{t_{n}} \int_{0}^{t_{n}} T(s) x_{n} d s+(1-\mu) v_{n}\right], \quad \forall n \geq 1,
\end{gathered}
$$

where $\mu \in(0,1),\left\{\alpha_{n}\right\}_{n=1}^{\infty},\left\{\beta_{n}\right\}_{n=1}^{\infty}$ are the sequences in $(0,1)$ which satisfies $\alpha_{n}+\beta_{n} \leq 1$ and $\left\{t_{n}\right\}_{n=1}^{\infty}$ is a positive real divergent sequence satisfy the following restrictions:

(C1) $\lim _{n \rightarrow \infty} \alpha_{n}=0$ and $\sum_{n=1}^{\infty} \alpha_{n}=\infty$,

(C2) $0<\lim \inf _{n \rightarrow \infty} \beta_{n} \leq \lim \sup _{n \rightarrow \infty} \beta_{n}<1$,

(C3) $\lim _{n \rightarrow \infty}\left(\left|t_{n+1}-t_{n}\right| / t_{n+1}\right)=0$.

Then the sequence $\left\{x_{n}\right\}$ defined by (4.8) converges strongly to $x^{*}$, which $x^{*}$ solves the variational inequality

$$
\left\langle(\gamma f-A) x^{*}, J\left(z-x^{*}\right)\right\rangle \leq 0, \quad \forall z \in \Omega,
$$

and $\left(x^{*}, y^{*}\right)$ is a solution of system of variational inequality problem $(1.16)$, where $y^{*}=J_{\left(M, \rho_{2}\right)}\left(x^{*}-\right.$ $\left.\rho_{2} B x^{*}\right)$. 


\section{Acknowledgments}

The authors wish to express gratitude to the referees for their careful reading of the manuscript and helpful suggestions. This research was partially supported by the Centre of Excellence in Mathematics under the Commission on Higher Education, Thailand, and P. Sunthrayuth was partially supported by the Centre of Excellence in Mathematics for Ph.D. Program at KMUTT. Moreover, we also would like to thank the Higher Education Research Promotion and National Research University Project of Thailand, Office of the Higher Education Commission for financial support (under the CSEC project no. 54000267).

\section{References}

[1] K. Ball, E. A. Carlen, and E. H. Lieb, "Sharp uniform convexity and smoothness inequalities for trace norms," Inventiones Mathematicae, vol. 115, no. 1, pp. 463-482, 1994.

[2] F. E. Browder, "Fixed-point theorems for noncompact mappings in Hilbert space," Proceedings of the National Academy of Sciences of the United States of America, vol. 53, no. 6, pp. 1272-1276, 1965.

[3] F. E. Browder, "Nonexpansive nonlinear operators in a Banach space," Proceedings of the National Academy of Sciences of the United States of America, vol. 54, no. 4, pp. 1041-1044, 1965.

[4] F. E. Browder and W. V. Petryshyn, "Construction of fixed points of nonlinear mappings in Hilbert space," Journal of Mathematical Analysis and Applications, vol. 20, no. 2, pp. 197-228, 1967.

[5] R. U. Verma, "Approximation-solvability of a class of A-monotone variational inclusion problems," Journal of the Korean Society for Industrial and Applied Mathematics, vol. 8, no. 1, pp. 55-66, 2004.

[6] R. U. Verma, "General over-relaxed proximal point algorithm involving A-maximal relaxed monotone mappings with applications," Nonlinear Analysis: Theory, Methods and Applications, vol. 71, no. 12, pp. e1461-e1472, 2009.

[7] R. U. Verma, "A-monotonicity and applications to nonlinear variational inclusion problems," Journal of Applied Mathematics and Stochastic Analysis, vol. 2004, no. 2, pp. 193-195, 2004.

[8] X. Qin, S. S. Chang, Y. J. Cho, and S. M. Kang, "Approximation of solutions to a system of variational inclusions in Banach spaces," Journal of Inequalities and Applications, vol. 2010, Article ID 916806, 16 pages, 2010.

[9] S. S. Zhang, J. H. W. Lee, and C. K. Chan, "Algorithms of common solutions to quasi variational inclusion and fixed point problems," Applied Mathematics and Mechanics, vol. 29, no. 5, pp. 571-581, 2008.

[10] K. Aoyama, H. Iiduka, and W. Takahashi, "Weak convergence of an iterative sequence for accretive operators in Banach spaces," Fixed Point Theory and Applications, vol. 2006, Article ID 35390, 13 pages, 2006.

[11] S. Reich, "Asymptotic behavior of contractions in Banach spaces," Journal of Mathematical Analysis and Applications, vol. 44, no. 1, pp. 57-70, 1973.

[12] S. Kitahara and W. Takahashi, "Image recovery by convex combinations of sunny nonexpansive retractions," Topological Methods in Nonlinear Analysis, vol. 2, no. 2, pp. 333-342, 1993.

[13] F. E. Browder, "Fixed-point theorems for noncompact mappings in Hilbert space," Proceedings of the National Academy of Sciences of the United States of America, vol. 53, pp. 1272-1276, 1965.

[14] S. Reich, "Strong convergence theorems for resolvents of accretive operators in Banach spaces," Journal of Mathematical Analysis and Applications, vol. 75, no. 1, pp. 287-292, 1980.

[15] L. C. Ceng, C. Y. Wang, and J. C. Yao, "Strong convergence theorems by a relaxed extragradient method for a general system of variational inequalities," Mathematical Methods of Operations Research, vol. 67, no. 3, pp. 375-390, 2008.

[16] Y. J. Cho, Y. Yao, and H. Zhou, "Strong convergence of an iterative algorithm for accretive operators in Banach spaces," Journal of Computational Analysis and Applications, vol. 10, no. 1, pp. 113-125, 2008.

[17] Y. Hao, "Strong convergence of an iterative method for inverse strongly accretive operators," Journal of Inequalities and Applications, vol. 2008, Article ID 420989, 9 pages, 2008.

[18] T. Jitpeera and P. Kumam, “A general iterative algorithm for generalized mixed equilibrium problems and variational inclusions approach to variational inequalities," International Journal of Mathematics and Mathematical Sciences, vol. 2011, Article ID 619813, 25 pages, 2011. 
[19] T. Jitpeera and P. Kumam, "A new hybrid algorithm for a system of mixed equilibrium problems, fixed point problems for nonexpansive semigroup, and variational inclusion problem," Fixed Point Theory and Applications, vol. 2011, Article ID 217407, 27 pages, 2011.

[20] P. Kumam, "A relaxed extragradient approximation method of two inverse-strongly monotone mappings for a general system of variational inequalities, fixed point and equilibrium problems," Bulletin of the Iranian Mathematical Society, vol. 36, no. 1, pp. 227-252, 2010.

[21] P. Katchang and P. Kumam, "A general iterative method of fixed points for mixed equilibrium problems and variational inclusion problems," Journal of Inequalities and Applications, vol. 2010, Article ID 370197, 25 pages, 2010.

[22] W. Kumam and P. Kumam, "Hybrid iterative scheme by a relaxed extragradient method for solutions of equilibrium problems and a general system of variational inequalities with application to optimization," Nonlinear Analysis: Hybrid Systems, vol. 3, no. 4, pp. 640-656, 2009.

[23] W. Kumam, P. Junlouchai, and P. Kumam, "Generalized systems of variational inequalities and projection methods for inverse-strongly monotone mappings," Discrete Dynamics in Nature and Society, vol. 2011, Article ID 976505, 24 pages, 2011.

[24] W. Kumam, C. Jaiboon, P. Kumam, and A. Singta, "A shrinking projection method for generalized mixed equilibrium problems, variational inclusion problems and a finite family of quasinonexpansive mappings," Journal of Inequalities and Applications, vol. 2010, Article ID 458247, 25 pages, 2010.

[25] N. Onjai-uea and P. Kumam, "Algorithms of common solutions to generalized mixed equilibrium problems and a system of quasivariational inclusions for two difference nonlinear operators in Banach spaces," Fixed Point Theory and Applications, vol. 2011, Article ID 601910, 23 pages, 2011.

[26] N. Petrot, R. Wangkeeree, and P. Kumam, "A viscosity approximation method of common solutions for quasi variational inclusion and fixed point problems," Fixed Point Theory, vol. 12, no. 1, pp. 165178, 2011.

[27] Y. Yao, M. A. Noor, K. I. Noor, Y. C. Liou, and H. Yaqoob, “Modified extragradient methods for a system of variational inequalities in Banach spaces," Acta Applicandae Mathematicae, pp. 1-14, 2009.

[28] K. Geobel and W. A. Kirk, Topics in Metric Fixed Point Theory, vol. 28 of Cambridge Studies in Advanced Mathematics, Cambridge University Press, New York, NY, USA, 1990.

[29] H. K. Xu, "An iterative approach to quadratic optimization," Journal of Optimization Theory and Applications, vol. 116, no. 3, pp. 659-678, 2003.

[30] H. K. Xu, "Iterative algorithms for nonlinear operators," Journal of the London Mathematical Society, vol. 66, no. 1, pp. 240-256, 2002.

[31] I. Yamada, "The hybrid steepest descent method for the variational inequality problem of the intersection of fixed point sets for nonexpansive mappings," in Inherently Parallel Algorithms for Feasibility and Optimization, K. Butnariu, Y. Censor, and S. Reich, Eds., pp. 473-504, Elsevier, New York, NY, USA, 2001.

[32] I. Yamada, N. Ogura, Y. Yamashita, and K. Sakaniwa, "Quadratic approximation of fixed points of nonexpansive mappings in Hilbert spaces," Numerical Functional Analysis and Optimization, vol. 19, pp. 165-190, 1998.

[33] A. Moudafi, "Viscosity approximation methods for fixed-points problems," Journal of Mathematical Analysis and Applications, vol. 241, no. 1, pp. 46-55, 2000.

[34] G. Marino and H. K. Xu, "A general iterative method for nonexpansive mappings in Hilbert spaces," Journal of Mathematical Analysis and Applications, vol. 318, no. 1, pp. 43-52, 2006.

[35] G. Cai and C. S. Hu, "Strong convergence theorems of a general iterative process for a finite family of $\lambda_{i}$-strict pseudo-contractions in q-uniformly smooth Banach spaces," Computers and Mathematics with Applications, vol. 59, no. 1, pp. 149-160, 2010.

[36] P. Sunthrayuth and P. Kumam, "A general iterative algorithm for the solution of variational inequalities for a nonexpansive semigroup in Banach spaces," Journal of Nonlinear Analysis and Optimization: Theory and Applications, vol. 1, no. 1, pp. 139-150, 2010.

[37] U. Kamraksa and R. Wangkeeree, "A general iterative process for solving a system of variational inclusions in Banach spaces," Journal of Inequalities and Applications, vol. 2010, Article ID 190126, 24 pages, 2010.

[38] K. Aoyama, Y. Kimura, W. Takahashi, and M. Toyoda, "On a strongly nonexpansive sequence in Hilbert spaces," Journal of Nonlinear and Convex Analysis, vol. 8, no. 3, pp. 471-489, 2007. 
[39] H. K. Xu, "Inequalities in Banach spaces with applications," Nonlinear Analysis: Theory, Methods and Applications, vol. 16, no. 12, pp. 1127-1138, 1991.

[40] L. S. Liu, "Ishikawa and Mann iterative process with errors for nonlinear strongly accretive mappings in Banach spaces," Journal of Mathematical Analysis and Applications, vol. 194, no. 1, pp. 114-125, 1995.

[41] A. Aleyner and Y. Censor, "Best approximation to common fixed points of a semigroup of nonexpansive operator," Nonlinear Convex Analysis, vol. 6, no. 1, pp. 137-151, 2005.

[42] A. Aleyner and S. Reich, "An explicit construction of sunny nonexpansive retractions in Banach spaces," Fixed Point Theory and Applications, vol. 2005, no. 3, pp. 295-305, 2005.

[43] T. D. Benavides, G. L. Acedo, and H. K. Xu, "Construction of sunny nonexpansive retractions in Banach spaces," Bulletin of the Australian Mathematical Society, vol. 66, no. 1, pp. 9-16, 2002.

[44] R. Chen and Y. Song, "Convergence to common fixed point of nonexpansive semigroups," Journal of Computational and Applied Mathematics, vol. 200, no. 2, pp. 566-575, 2007.

[45] Y. Song and R. Chen, "Strong convergence theorems for nonexpansive semigroup in Banach spaces," Journal of Mathematical Analysis and Applications, vol. 338, no. 1, pp. 152-161, 2008.

[46] X. N. Li and J. S. Gu, "Strong convergence of modified Ishikawa iteration for a nonexpansive semigroup in Banach spaces," Nonlinear Analysis, Theory, Methods and Applications, vol. 73, no. 4, pp. 1085-1092, 2010.

[47] R. E. Bruck, "Properties of fixed point sets of nonexpansive mappings in Banach spaces," Transactions of the American Mathematical Society, vol. 179, pp. 251-262, 1973.

[48] T. Suzuki, "Strong convergence of Krasnoselskii and Mann's type sequences for one-parameter nonexpansive semigroups without Bochner integrals," Journal of Mathematical Analysis and Applications, vol. 305, no. 1, pp. 227-239, 2005.

[49] J. P. Gossez and E. Lami Dozo, "Some geometric properties related to the fixed points theory for nonexpansive mappings," Pacific Journal of Mathematics, vol. 40, pp. 565-573, 1972.

[50] J. S. Jung, "Iterative approaches to common fixed points of nonexpansive mappings in Banach spaces," Journal of Mathematical Analysis and Applications, vol. 302, no. 2, pp. 509-520, 2005.

[51] J. Schu, "Approximation of fixed points of asymptotically nonexpansive mappings," Proceeding American Mathematical Society, vol. 112, pp. 143-151, 1991. 


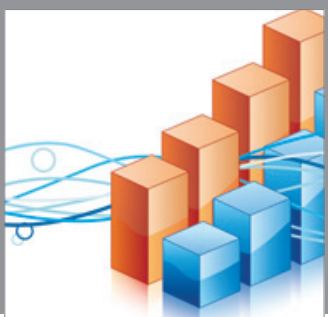

Advances in

Operations Research

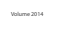

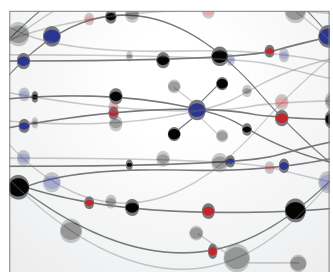

\section{The Scientific} World Journal
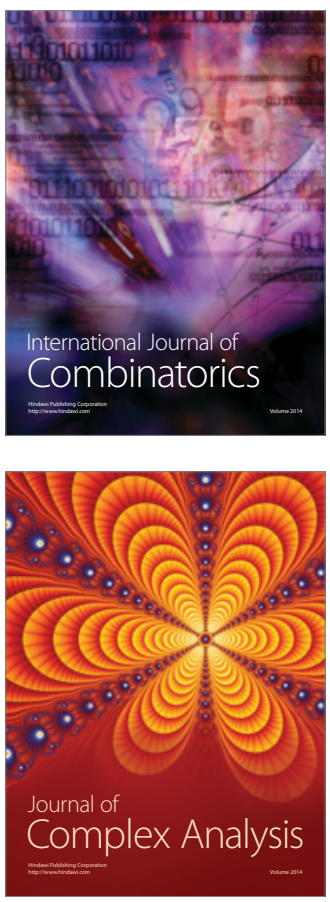

International Journal of

Mathematics and

Mathematical

Sciences
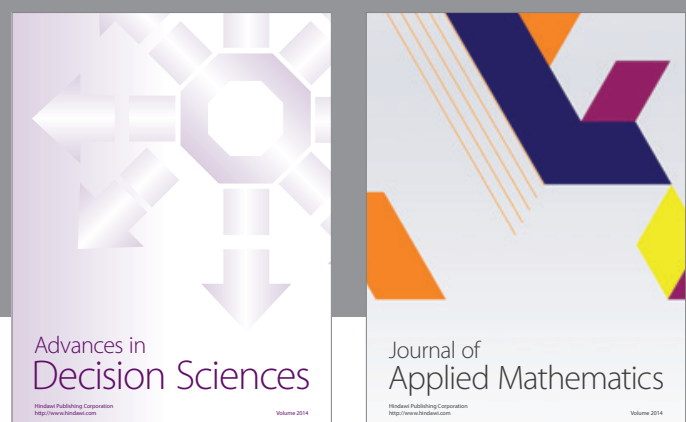

Journal of

Applied Mathematics
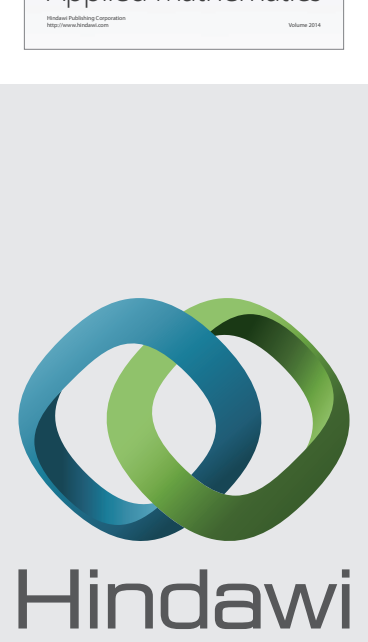

Submit your manuscripts at http://www.hindawi.com
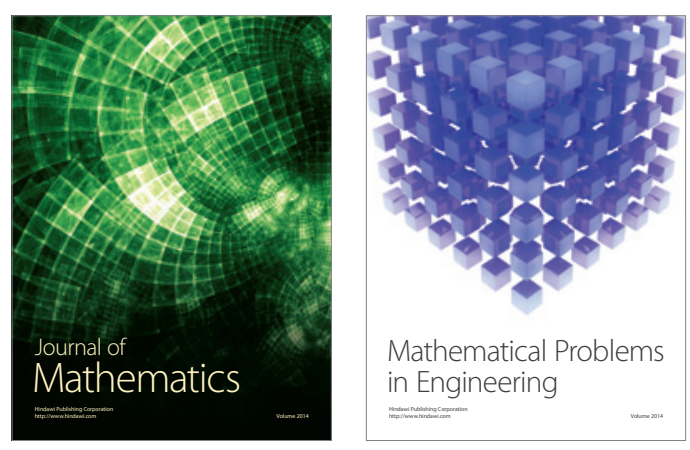

Mathematical Problems in Engineering
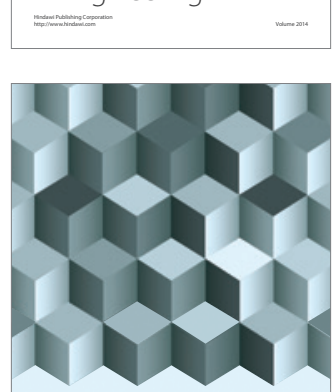

Journal of

Function Spaces
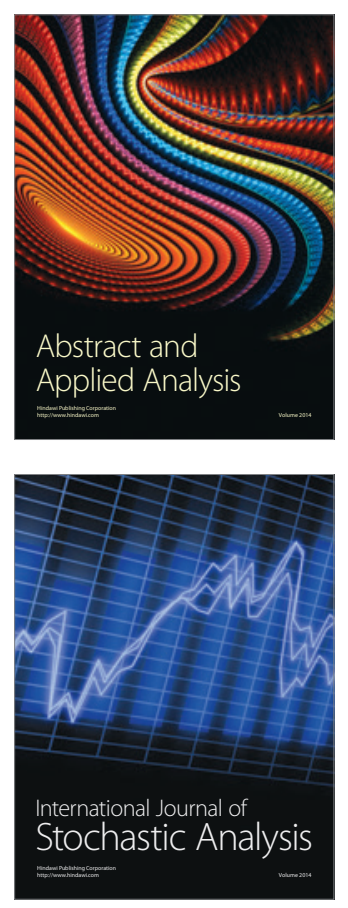

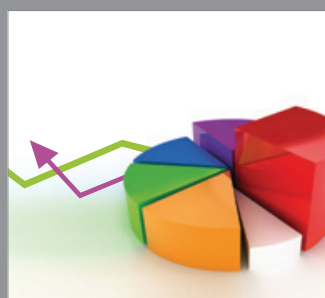

ournal of

Probability and Statistics

Promensencen
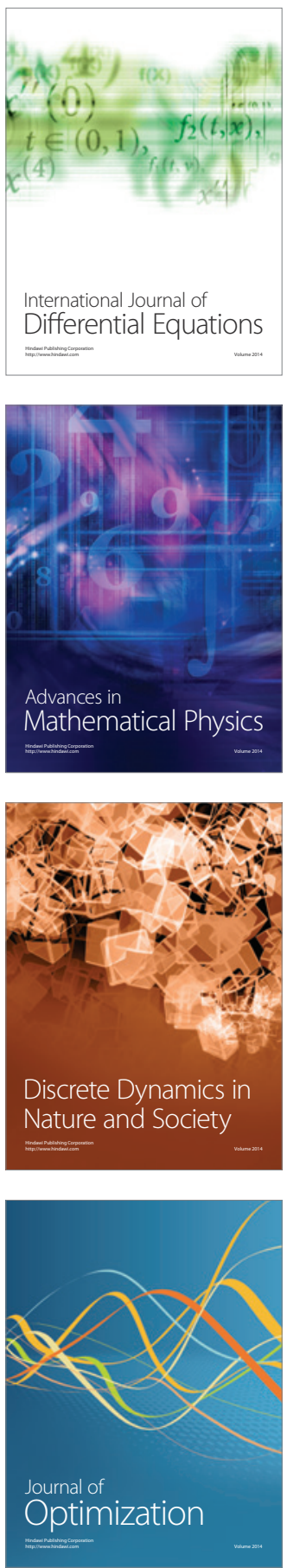